\title{
Denizüstü/Karaüstü Rüzgâr Santralinin Modellenmesi ve Şebekeye Bağlantısı
}

\author{
Ozan Akdağ ${ }^{1 *}$, Celaleddin Yeroğlu ${ }^{2}$ \\ ${ }^{1}$ İnönü Üniversitesi, Mühendislik Fakültesi, Bilgisayar Mühendisliği Bölümü, Malatya, Türkiye(ORCID: 0000-0001-8163-8898) \\ 2̇̇nönü Üniversitesi, Mühendislik Fakültesi, Bilgisayar Mühendisliği Bölümü, Malatya, Türkiye(ORCID: 0000-0002-6106-2374)
}

(İlk Geliş Tarihi 30 Aralık 2018 ve Kabul Tarihi 5 Temmuz 2019)

(DOI: 10.31590/ejosat.505340)

ATIF/REFERENCE: Akdağ, O. \& Yeroğlu, C. (2019). Denizüstü/Karaüstü Rüzgâr Santralinin Modellenmesi ve Şebekeye Bağlantısı. Avrupa Bilim ve Teknoloji Dergisi, (16), 505-520.

$\ddot{O} \mathbf{z}$

Büyüyen rüzgâr enerji piyasasında karasal alanlarda oluşan kısıtlamalar nedeniyle denizüstü rüzgâr santralleri dünya genelinde yaygınlaşmaktadır. Denizüstü rüzgâr santrallerinin karaüstü rüzgâr santrale göre maliyetlerinin yüksek olmasına rağmen, kaynak kalitesinin yüksek oluşu bu durumu elimine etmektedir. Bunun yanında günümüzde gelişen teknoloji ile düşen maliyetler denizüstü santralleri karaüstü rüzgâr santrallere göre gittikçe cazip kılmaktadır. Denizüstü santrallerin dünyada özellikle 2010 yılından sonra kurulu gücünde önemli artışlar olmuştur. Bu artışda sektörel gelişmeler, enerji güvenliği, küresel ssınma sorununu aşma gibi konular etkili olmuştur. Denizüstü rüzgâr santralleri, son yıllarda tüm dünyada hızla yaygınlaşmaktadır. Ülkemizde ise henüz devreye alınmış bir denizüstü rüzgâr santrali bulunmamaktadır. Ülkemizde denizüstü rüzgâr santrallerinde işletme deneyimi eksikliği, planlama, devreye alma, şebeke bağlantı gibi konularda geliştirici çalışmaların yapılmasına ihtiyaç vardır. Bu çalışmada denizüstü rüzgâr santralinin kurulum/modelleme aşamaları ve ilgili şebekeye bağlantı esasları incelenmiş̧ir. Örnek olarak Çanakkale ilinin Ezine ilçesi yakınlarında toplam $40 \mathrm{MW}$ denizüstü, $40 \mathrm{MW}$ klasik bir rüzgar santralinin (karaüstü) birlikte o bölgeye en yakın 154/34,5kV transformatör merkezinin $154 \mathrm{kV}$ 'lık barasına dâhil edilmesi senaryosu için bu santralin sanal modeli oluşturulup güç sistemine bağlantı esasları analiz edilmiştir.

Anahtar Kelimeler: Denizüstü rüzgâr santrali, Yük akış analizi, Kısa devre analizi, Voltaj kaynağı dönüştürücü.

\section{Modeling of Offshore/Onshore Wind Power Plant and Network Connections}

\begin{abstract}
Offshore wind farms are becoming widespread all over the world due to restrictions in the terrestrial areas in the growing wind energy market. Although the cost of offshore power plants is higher compared to onshore power plants, high resource quality eliminates this situation. In addition, today's developing technology and falling costs make offshore power plants more attractive than onshore power plants. There have been significant increases in the installed capacity of offshore power plants in the world, especially after 2010 . Sectoral developments, energy security and the problem of global warming were effective in this increase. Offshore wind farms is gaining popularity all over the world in recent years.In our country, there is no offshore wind power plant yet.Offshore wind power plants in our country; there is a need to carry out developer work on issues such as to lack of operating experience, planning, commissioning and network connection.In this study, the installation/modeling stages of the offshore wind power plant are examined and then the connection principles to the related network are investigated.As an example, a virtual model of the power plant is obtained based on the scenario that a $40 \mathrm{MW}$ offshore and a $40 \mathrm{MW}$ classical wind power plant (onshore) near the Ezine district of
\end{abstract}

${ }^{1}$ Sorumlu Yazar: İnönü Üniversitesi, Mühendislik Fakültesi, Bilgisayar Mühendisliği Bölümü, Malatya, Türkiye(ORCID: 0000-0001-81638898),ozanakdag@live.com 


\section{Avrupa Bilim ve Teknoloji Dergisi}

Çanakkale province are connected to $154 \mathrm{kV}$ bus bar of the $154 / 34,5 \mathrm{kV}$ transformer center and the virtual connection principles to the power system network were investigated.

(Minimum 250 - Maximum of 400 words and content should be written in a way to include material, method, findings and results.)

Keywords: Offshore wind farm, Load flow analysis, Short circuit analysis, Voltage supply converter.

\section{Giriş}

Günümüzdeki teknolojik gelişmeler, insan nüfusunun artışı ve doğal kaynakların hızla azalması ile yenilenebilir enerji kaynaklarına yönelim artırmıştır. Yenilebilir enerji kaynakları kendi kaynağını sürekli kullanabilen enerji kaynaklarıdır. Yenilenebilir enerji, sürdürülebilen enerji politikaları açısından, iklim değiş̧ikliği ve küresel ısınmanın verdiği zararlı etkilerin azaltılması yönünden önemlidir (Efe, 2014). Rüzgâr, güneş, denizüstü rüzgâr vb. santraller potansiyellerinin yüksek olduğu yerler sera gazlarını indirgemede büyük bir potansiyele sahiptir (Nanou ve Papathanassiou, 2016). Bu gibi özelliklerinden dolayı tüm dünyada olduğu gibi ülkemizde de yenilenebilir enerji kaynaklarına ilgi artmaktadır. Yenilenebilir enerji kaynaklarından birisi olan denizüstü rüzgâr santralleri bazı avantajlarından dolayı klasik rüzgâr santralleri ile rekabet edecek gibi görülmektedir. Klasik rüzgâr santrallerinin (karaüstü rüzgar santrali) karada özellikle engebeli arazilerde kurulumunun sağlanması, karasal alan gereksiniminin olması, açık denizlere göre rüzgâr potansiyelinin az olması, rüzgâr akışının karada açık denizlere göre istikrarsız olması vb. gibi durumlardan dolayı denizüstü rüzgâr santrallerine olan talep artmaktadır (Koroglu, 2011). Diğer taraftan denizüstü rüzgâr santralleri, klasik rüzgâr santrallerine göre daha karmaşık yapıdadır. Denizüstü rüzgâr santralleri dünyanın büyük bir bölümünün okyanus ve denizlerden oluşmasından dolayı büyük bir gelişme potansiyeline sahiptir. Bu yüzden Avrupa Birliği (AB) enerji politikalarında önemli bir yere sahiptir. AB'nin stratejik enerji planlamaları dâhilinde 2050 yılına kadar, $188 \mathrm{GW}$ ve $460 \mathrm{GW}$ kurulu güce sahip okyanus enerjisinden çeşitli yöntemler ile enerji elde edilmesine dayalı santral kurulmasını planlanmaktadır (Perez ve ark., 2014). Ülkemizde ise toplam yenilenebilir enerjiye dayalı santrallerin üretim kapasitesi 2023'e kadar 20 GW çıkarılması planlanmaktadır (Karık ve ark., 2017). Bu planlamadan dolayı ülkemizde teşvik, yatıımcı bilinçlendirme ve alt yapı yatırımlarının yapılması gibi birçok çalışma yapılmaktadır. Türkiye Enerji Bakanlığı ülkemizin ilk denizüstü rüzgâr santralinin (1200 MW) yapılma çalışmalarını 2018'in sonunda başlayacaktır. Literatürde genelde Türkiye'nin denizüstü rüzgâr santralinin potansiyelinin değerlendirilmesi ve teknik maliyeti üzerine çalışmalar bulunmaktadır. Bu çalışmalara örnek olarak, Argin ve Yerci Türkiye'de Karadeniz Bölgesi'nin deniz üstü rüzgâr potansiyelini WASP yazılımı kullanarak tespit etmişlerdir (Argin ve Yerci 2017). Cali ve arkadaşları yaptığı çalışmada Bozcaada'nın deniz üstü rüzgâr potansiyeli değerlendirip tekno-ekonomik analizini yapmışlardır (Cali ve ark., 2018). Satir ve arkadaşları ise yaptığı çalışmada Ege Denizde WINDPRO yazılımı kullanarak, bu bölgenin deniz üstü rüzgâr potansiyelini değerlendirip, tekno-ekonomik analizini yapmışlardır (Satir ve ark., 2018). Bu çalışmada ise örnek bir denizüstü rüzgar santralinin klasik bir rüzgar santrali ile Türkiye iletim sistemine entegre edilmesi çalışması, denizüstü rüzgar teknolojisi açıklanarak yapılmıştır. Sonrasında bu güç sisteminde yük akış, kısa devre, dinamik simulasyon analizi yapılmıştır. Böylece bu yayının Türkiye'de bu konuda yapılacak çalışmalara yol gösterici nitelik de olması düşünülmüştür.

Bu yayın aşağıdaki bölümlerde ele alınmıştır. Bunlar;

- Denizüstü rüzgâr santral sistemi, VSC (Voltage Source Control),

- Ön saha çalışması,

- Denizüstü/Karaüsütü rüzgâr santrali ve 154 kV Çanakkale civarı iletim sisteminin modellenmesi,

- Yük akış ve kısa devre arıza analizi,

- Dinamik Simülasyon analizi,

- Karaüstü rüzgâr santralinin reaktif güç kapasite analizi (P/Q-V/Q Diyagramı),

$\mathrm{Bu}$ aşamaların sanal modelde ele alınmasında, DigSilentPowerFactory V.15.1.6 (PowerFactory, 2017) yazılımı kullanılmıştır. Bu çalışma ilgili bölge için denizüstü rüzgâr santrallerinin şebeke bağlantı noktasındaki analizlerinin yapılması ve gerçek güç sistemine etkilerinin tartışılması yönünden ilk olma özelliği taşımaktadır.

\section{Materyal ve Metot}

\subsection{DENIZZ̈STÜ RÜZGÂR SANTRAL SISTEMI}

Denizüstü rüzgar santralini mevcut güç sistemine entegre etmede 2 yol vardır. Bunlar HVAC (Yüksek gerilimde AC iletim), HVDC (Yüksek gerilimde DC iletim)'dir. Tüm dünyada olduğu gibi ülkemizde enerji iletimi AC olarak yapılır. Bu iki sistem arasındaki dönüşüm işlemleri yüksek gerilimli doğru akım dönüştürücüler ile sağlanır (Shah ve ark., 2016). HVDC iletimi SVC (static var compensation) ve STATCOM gibi reaktif güç kompanzasyonuna ihtiyaç duymaz. Ayrıca deniz altı iletimde HVDC sistem daha uygundur. Bu yüzden özellikle kıyıdan uzak olan santrallerde HVDC iletimin kullanılması avantaj sağlar. Bu çalışmada oluşturulan güç sistemi Şekil 1'de görülen prensip şemasına sahiptir. Şekil 1'deki gibi HVDC sistemin kullanılıp tekrardan HVAC sisteme dönüştürülmesindeki amaç ülkemizde ilerleyen yıllarda bu dönüşüm sistemlerinin daha yaygın kullanılacağının ön görülmesinden dolayıdır. Şekil 1'de yer alan VSC (voltage source control) voltaj kaynağı dönüştürücüdür. VSC aktif güç ve gerilimi belirleyerek bir P-V ya da P-Q kontrolör olarak çalışır (Jerko, 2014). 


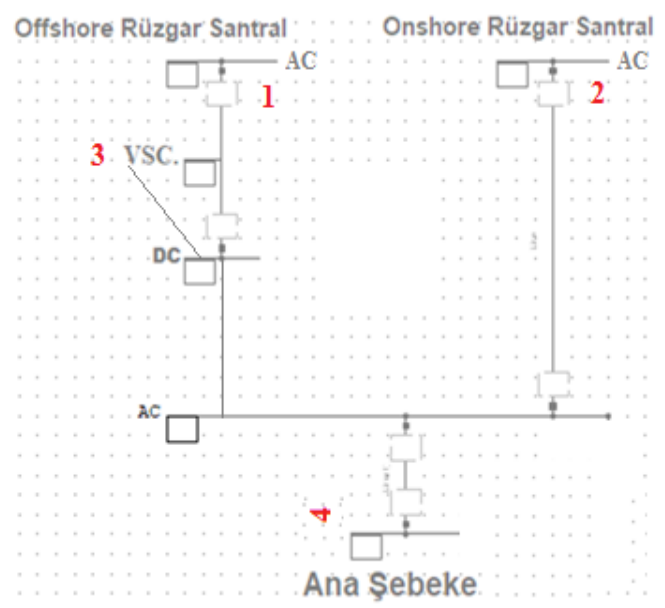

Şekil 1. Çalıșma için oluşturulan modelin basitleștirilmiş hali

\subsubsection{VSC}

Denizüstü rüzgâr santrallerinde VSC teknolojisi ile DC çok-terminalli şebekeler oluşturulabilir. VSC'lerin yapısı DC bileşenler ve diğer kontrol elemanlarının bir arada tutulması ile oluşur (Jerko, 2014). VSC teknolojisi önümüzdeki yıllarda ülkemizde DC iletim sistemlerinin artışı ile daha geniş kullanım alanı bulacaktır. İlerleyen yıllarda güç yoğunluğunun artışı ile mevcut iletim hatlarında güç kalitesi problemi ortaya çıkacaktır. Bu durumu önlemede VSC teknolojisi yardımcı olacaktır (Suwan ve Jordanien, 2017). VSC teknolojisinde yarı iletken malzemelerden oluşan IGBT modüller kullanılır. Gerilim dalga şekli üretmek için ise Darbe Genişlik Modülasyonu (PWM) kullanılır. PWM ile dalga şekli, faz açısı ve temel frekanslı bileşenlerin büyüklüğünün üretilmesi mümkündür (Suwan ve Jordanien, 2017). PWM ile aktif/reaktif güçler bağımsız olarak kontrol edilebilir. VSC-HVDC sisteminin temel çalışma prensibi Şekil 2'de görüldüğü gibidir (Van ve ark., 2009). AC reaktör olarak adlandırılan seri endüktans, AC iletim ağındaki sinusoidal akımı düzeltir. Ayrıca bu AC reaktör voltaj, akım, aktif/reaktif güç ölçümleri için referans nokta olacak şekilde kullanılabilir. DC tarafta yer alan şönt kapasitörler ise DC voltaj kaynağı ve güç sistemindeki harmoniklerin azaltılmasında kullanılır.

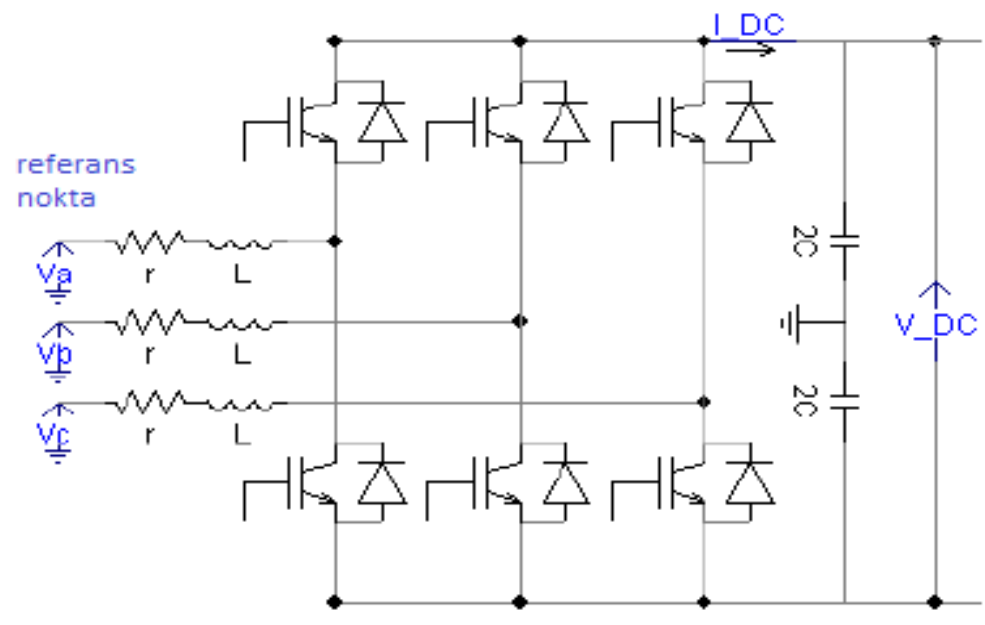

Şekil 2. VSC'nin içyapısı

\section{Araştırma Sonuçları ve Tartışma}

\section{1. Ön Saha Çalışması}

Denizüstü rüzgâr santrali kurulumunda: rüzgâr potansiyelinin belirlenmesi, deniz derinliğinin seviyesi, deniz tabanının genel yapısı ve santralin kıyıdan uzaklığı önemlidir. Denizüstü rüzgâr santrallerinde karadaki gibi yerden yüksek rüzgâr tribünlerine ihtiyaç yoktur. Çünkü açık denizde rüzgâr potansiyeli karaya göre daha yüksektir (Köroğlu, 2011). Bu çalışmada, ülkemizde Rüzgâr Enerji Santrali (RES) kurulumlarının oldukça yoğun olduğu ve bu RES'lerin verimlilik bakımından dünyada ilk sıralarda yer aldığı Çanakkale ili seçilmiştir. Şekil 3'de yenilenebilir Enerji Müdürlüğünden alınan Çanakkale iline ait global rüzgar hızı haritası görülmektedir. Şekil 3 incelendiğinde özellikle Çanakkale ilinin kıyı şeridinde rüzgâr hızı $7 \mathrm{~m} / \mathrm{s}$ 'nin üstünde olduğu görülmektedir (Canakkale, 2017). Bu bölgede ayrıca kapasite faktörü \%35'in üstündedir. Bu iki özellik yönünden Çanakkale ili RES kurulumuna oldukça müsaittir. Bu rüzgâr haritasında kurulması düşünülen denizüstü rüzgâr santralinin yaklaşık yeri gösterilmiştir. Ayrıca bu bölgeye çok yakın bir $154 \mathrm{kV}$ trafo merkezi olması da çok büyük bir avantajdır. Şekil 4'de Çanakkale ilinin Bozcaada ve Ezine ilçesi 
arası kıta sahanlığı/deniz derinliği görülmektedir. Şekil 4 incelendiğinde bu bölgeye ait Bozcaada ve Ezine ilçesi arasında kıta sahanlığı içinde kalan bölgelerde rüzgâr hızı potansiyelinin karaya yakın olduğu görülür. Bu bölgede deniz derinliği 2 km açıklığa kadar 0-10 metre arasında değişmektedir. Bu değerler denizüstü rüzgâr santrali kurulumu açısından uygundur. Sonuç olarak tüm bu belirtilen gerekçelerden dolayı denizüstü rüzgâr santrali bu çalışmada Ezine ilçesinin (Odunluk İskelesi civarı) kıyı şeridinde kurulması üzerine kurgulanmıştır.

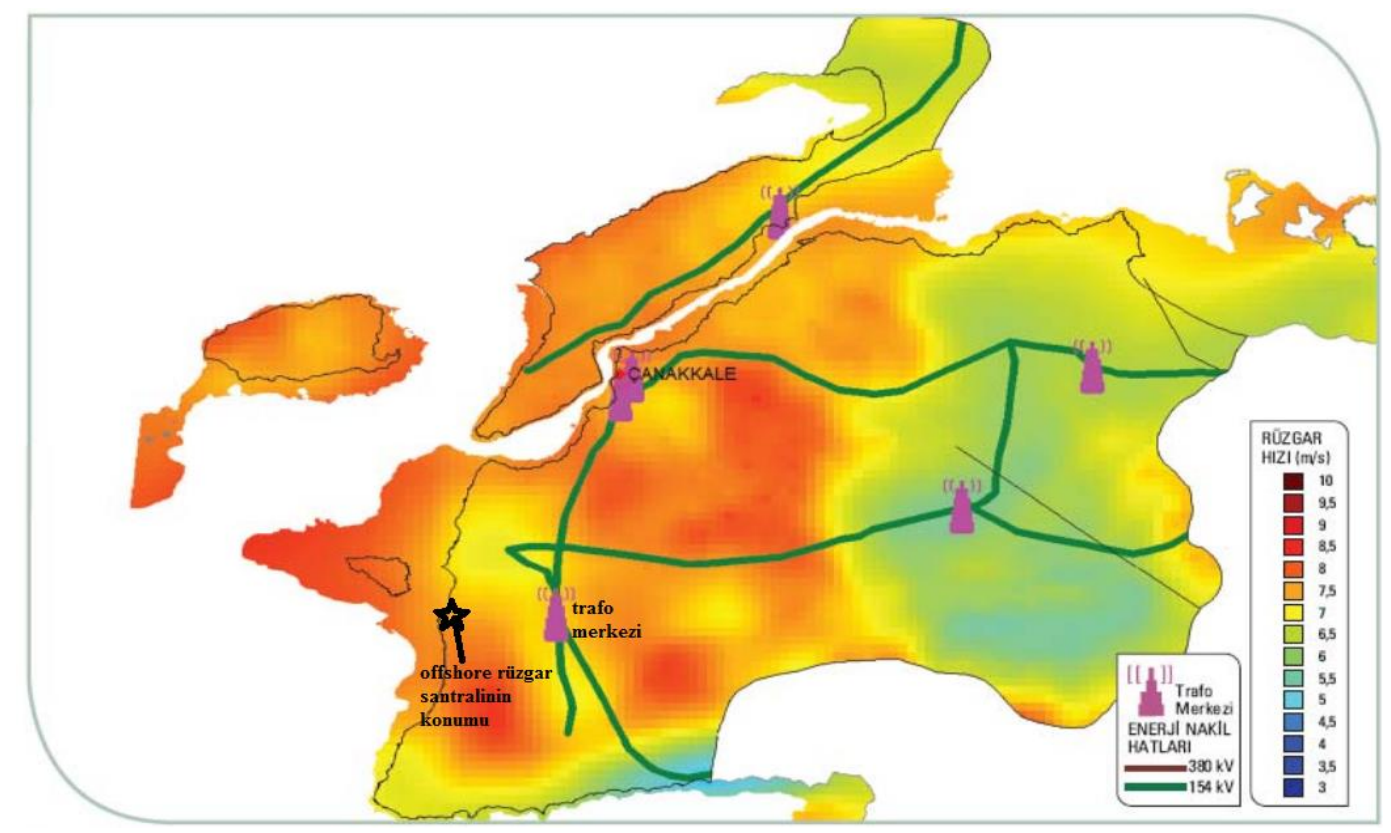

Şekil 3. Çanakkale Rüzgâr Haritası (Canakkale, 2017)

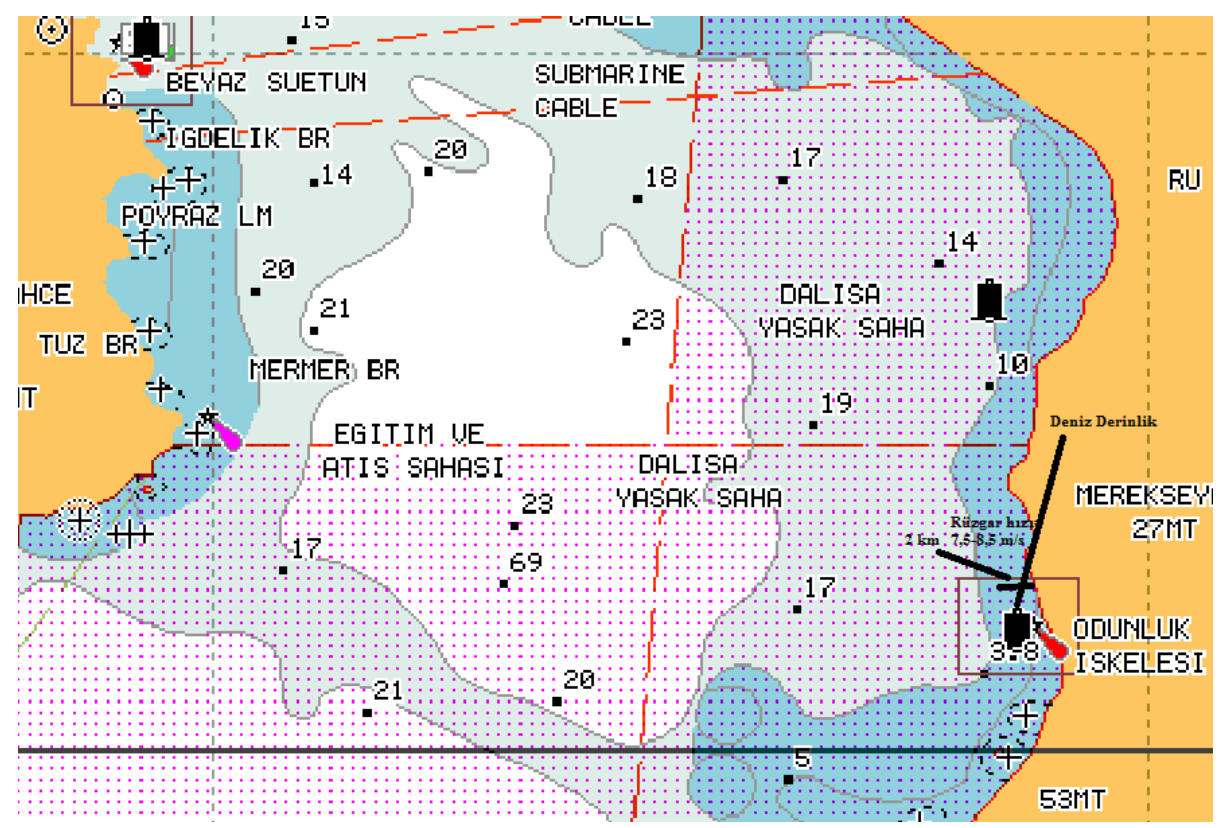

Şekil 4 . Denizüstü rüzgâr santralin kurulması önerilen bölge

\subsection{Güç Sisteminin Modellenmesi}

Şekil 1'de güç sisteminin basitleştirilmiş hali görülmektedir. Basitleştirilmiş bu modelde; güç sistemi bütün olarak 4 bölümde ele alınmıştır. Her bölümün DigSilent simülasyon yazılımında sanal modeli oluşturulmuştur. 


\subsubsection{Denizüstü Rüzgâr Santralinin Modellenmesi}

Denizüstü rüzgâr santrali toplam 8 adet rüzgâr tribününden oluşmaktadır. Rüzgâr tribünlerinin her birinin aktif gücü 5 MW, anma gerilimi 0,69 kV iken görünür gücü 5,5 MVA'dır. Rüzgar tribünlerinin her biri 33/0,69kV'lık güç trafosu ile $33 \mathrm{kV}$ 'lık baraya dâhil edilir. Daha sonra bu baradan 2 grup halinde, 2 adet 154/33 kV'lık güç trafosu ile 154 kV'luk AC_Denizüstü barasına bağlanır. Bu bağlantılar ve denizüstü rüzgâr santrallerine ait bara gerilimleri ve toplam ürettiği aktif/reaktif güç Şekil 5a'da görüldüğü gibidir. Şekil 5 b'de ise denizüstü santralin AC-DC-AC (HVDC) dönüşüm ünitesi görülmektedir.

\subsubsection{Karaüstü Rüzgâr Santralinin Modellenmesi}

Modellenen karaüstü rüzgâr tribünü Şekil 6’da görüldüğü gibidir. Rüzgâr tribünlerinin hızına göre ürettiği güç bilgileri ise Şekil 7' deki gibi DigSilent yazılımında oluşturulan sanal modele girilir. Karaüstü rüzgâr santrali, offhore rüzgâr santralinin hemen deniz kıyısında yer alacak şekilde düşünülmüştür. Karaüstü rüzgâr santrali, her biri $2.5 \mathrm{MW}$ 'dan 16 adet rüzgâr tribününden oluşmaktadır. Şekil 6’da gösterilen her bir rüzgâr tribünü 3 adet rüzgâr tribününü temsil etmektedir. Karaüstü ve denizüstü rüzgâr santralleri Şekil 1'de görüldüğü gibi $154 \mathrm{kV}$ baraya bağlanarak, ana şebeke ile ilişkilendirilir. Bu birleşik santralin toplam kurulu gücü bu çalışmada 80 MW olarak düşünülmüştür.

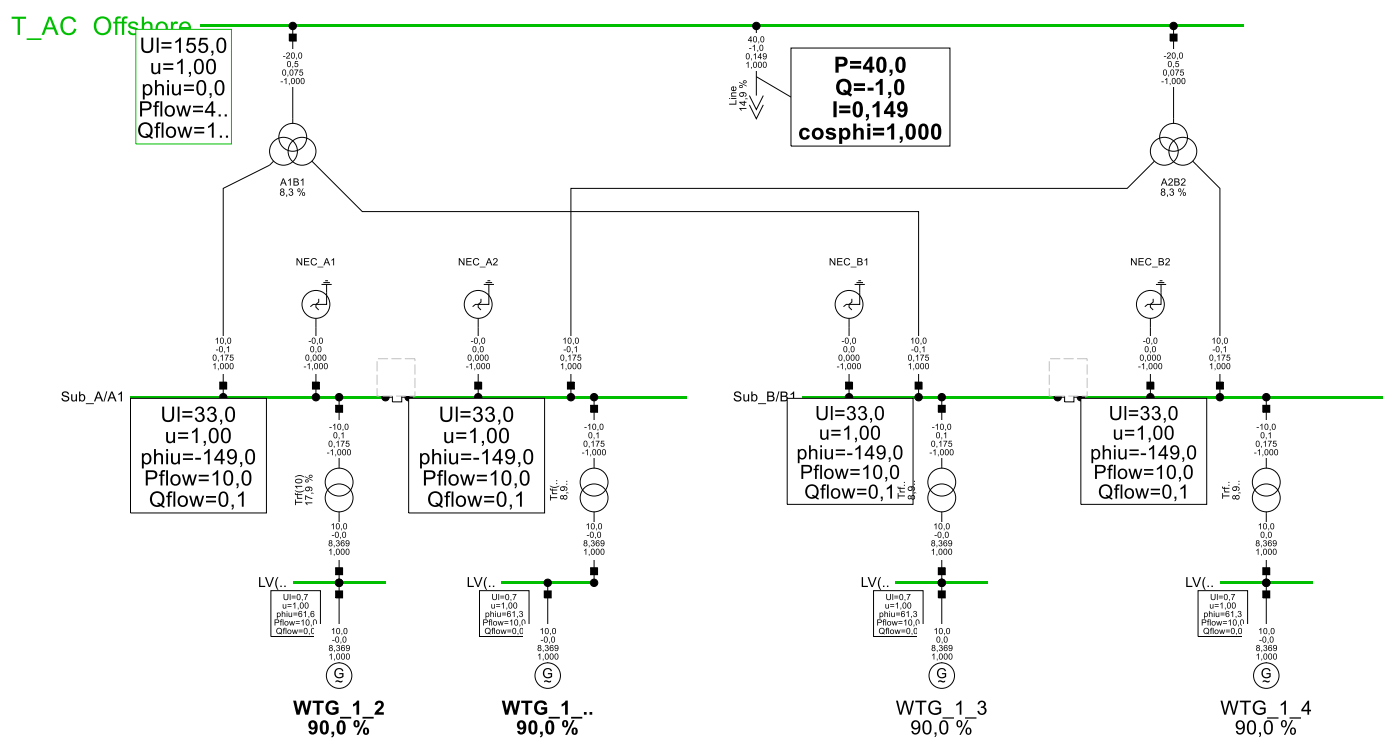

Şekil 5a. Denizüstü Rüzgâr Santralinin Modeli 


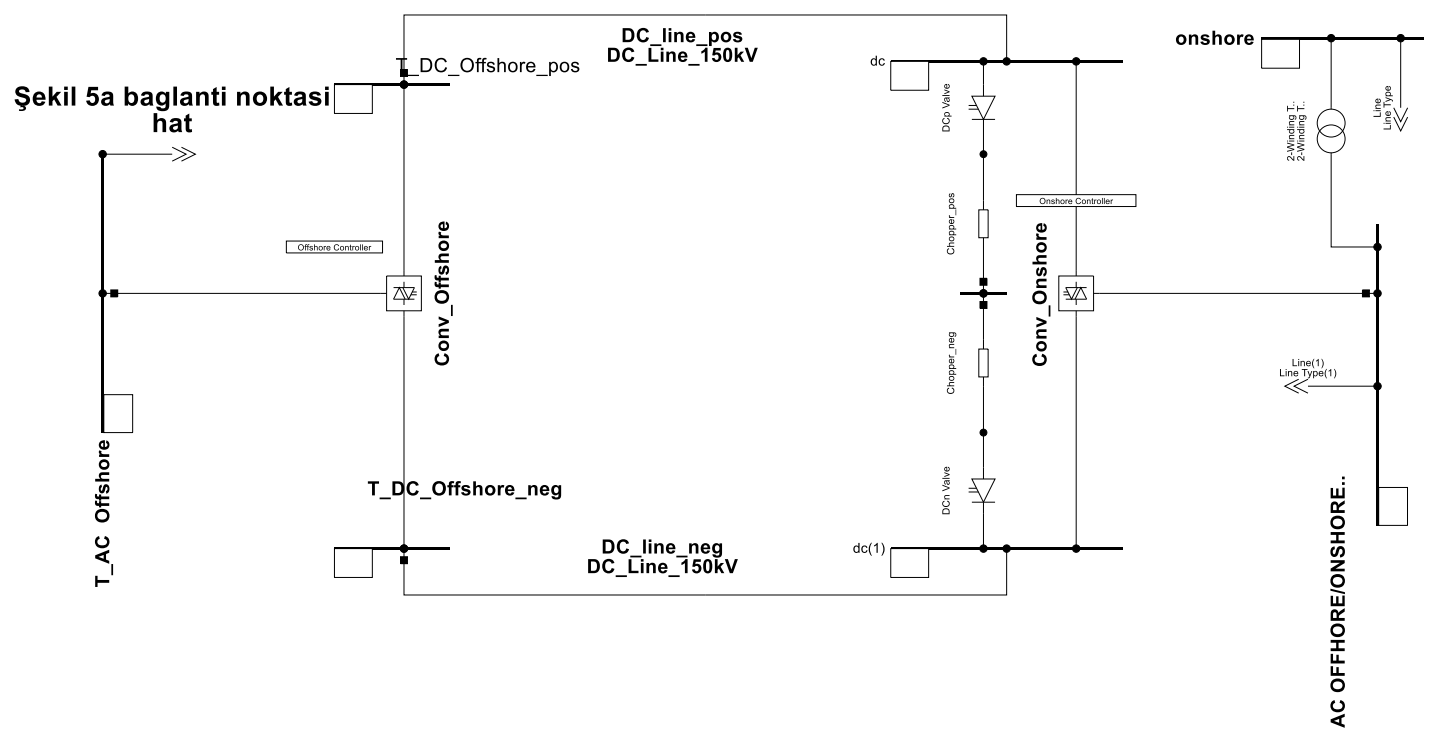

Şekil 5b.Denizüstü santralin HVDC ünitesi

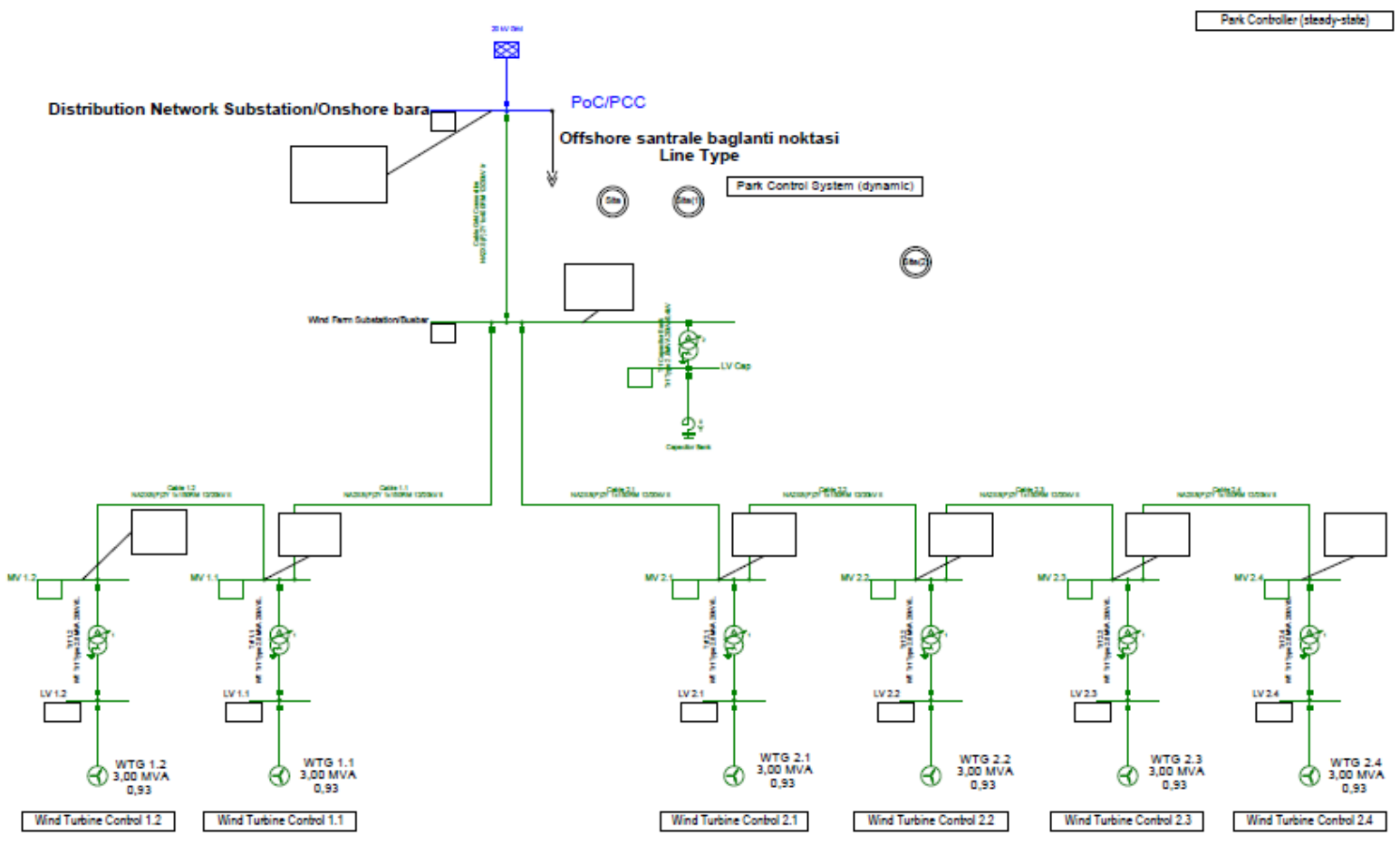

Şekil 6.Onshore Rüzgâr Santralinin Modeli 


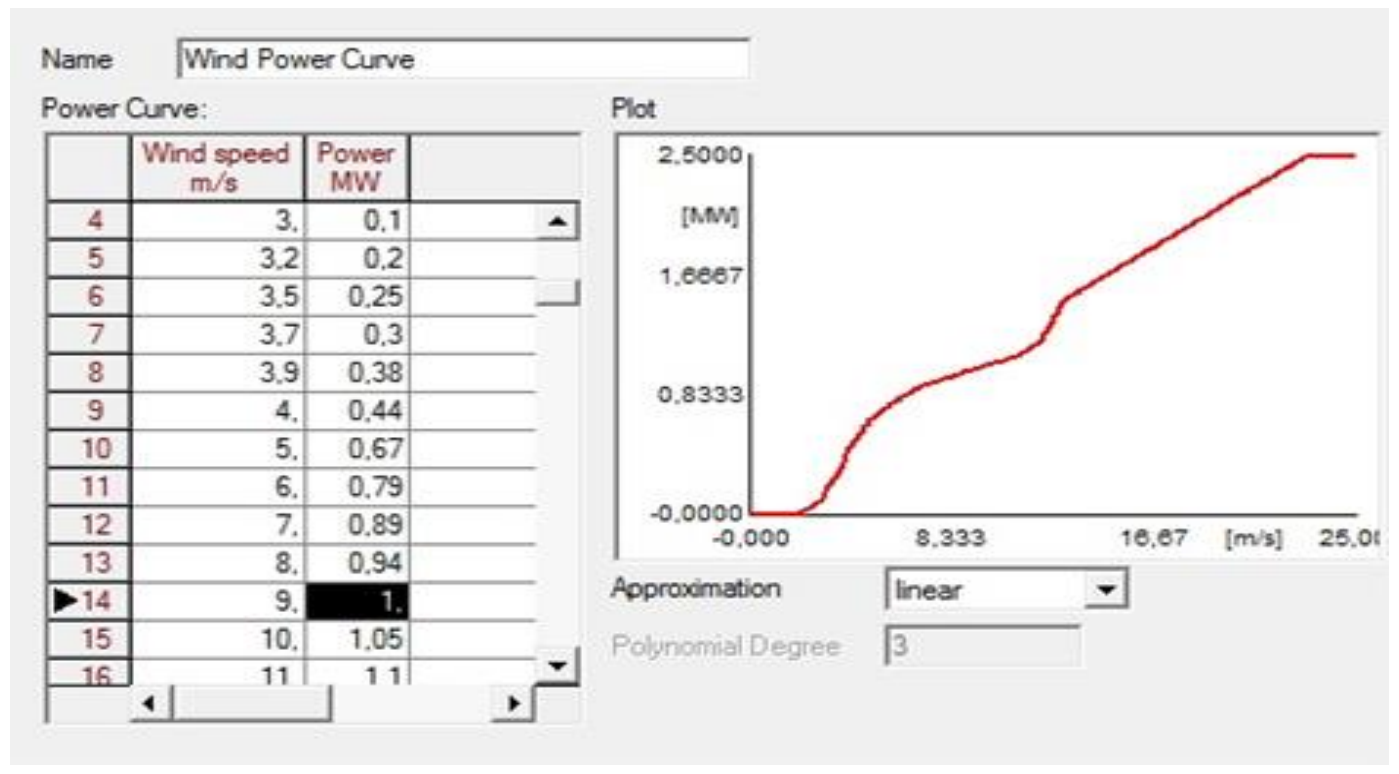

Şekil 7. Tasarlanan rüzgâr tribününün güç eğrisi

\subsubsection{VSC Modeli}

Çalışmadaki güç sisteminin ana yapısı Sekil 1'de görüldüğü gibidir. Çalışmada DC bağlantının kullanılması ilerde iletim sistemine, HVDC bir iletim ağının dâhil olma durumu varsayılarak yapılmıştır. HVDC bağlantısı, DigSilent Power Factory yazılımında bulunan VSC modülü ile sağlanmıştır. Bu modülde bulunan kontrolör ile denizüstü rüzgâr santralinin şebeke geriliminin kontrolü sağlanır. Bu işlem AC şebekedeki frekans ve voltajın sabit bir değerde tutulması ile sağlanır (DIgSILENT, 2018). Voltaj ve frekansın sabit değerde tutulmasının nedeni aktif ve reaktif güç değerlerinin kontrolünün sağlanamamasıdır. Șekil 8'de denizüstü HVDC kontrol sisteminin genel yapısı görülmektedir. Şekil 8 incelendiğinde santrale ait AC voltaj/akımı ve DC voltajı (+/-) tespit etmede kullanılan ölçüm modülleri görülmektedir. Kontrolörün AC voltaj büyüklüğü ve frekansı sabit bir değerde olmalıdır. Bu işlem Şekil 8'de görülen 'Pm' (modülasyon endeksi) ve PWM dönüştürücü giriş frekansı 'f0' ile yapıllır. Modülasyon endeksi, DC voltajlı (ileri yönlü besleme yapan) PI kontrolör ile kontrol edilir. Denizüstü dönüştürücü kontrolörün genel yapısı Şekil 9'da görüldüğü gibidir. Şekil 9 incelendiğinde ilk PI kontrol cihazı, AC voltaj sapmasını giriş sinyali olarak alıp, çıkışında reaktif akım üretir. 2. Kontrol cihazı PI ünitesinin çıkışı ise sonraki referans voltajının değeridir. Bu referans voltaj değeri uacudc_Feedforward bloğuna gelerek ölçülebilen voltaj değeri olan $u d c^{\prime} y e$ bölünüp bir sabit ile çarpılır. Bu blok PWM kontrol bloğu olarak bilinir. Pm'i (modülasyon endeksi) sınırlayıcı bir karakteristiğe sahiptir.

Bu kontrol yapısı genel olarak, reaktif akımı sınırlayıcı özelliktedir. Bu sınılama genelde bir arıza durumunda devreye girer. Bu durumda reaktif akım iq geri besleme yaparak, dönüştürücüdeki voltaj değerini ayarlar. Ayrıca santralde yüksek DC voltajı durumu oluşmasında, Denizüstü santralin frekansını istenilmeyen seviyede yükselir. Bu yükseliş kontrol ünitesi ile bir sinyal olarak, rüzgâr tribünlerine getirilir. Böylece rüzgâr tribünlerine getirilen bu sinyal aktif gücü düşürerek frekansın normale dönmesini sağlar. 
Frame Offshore VSC:

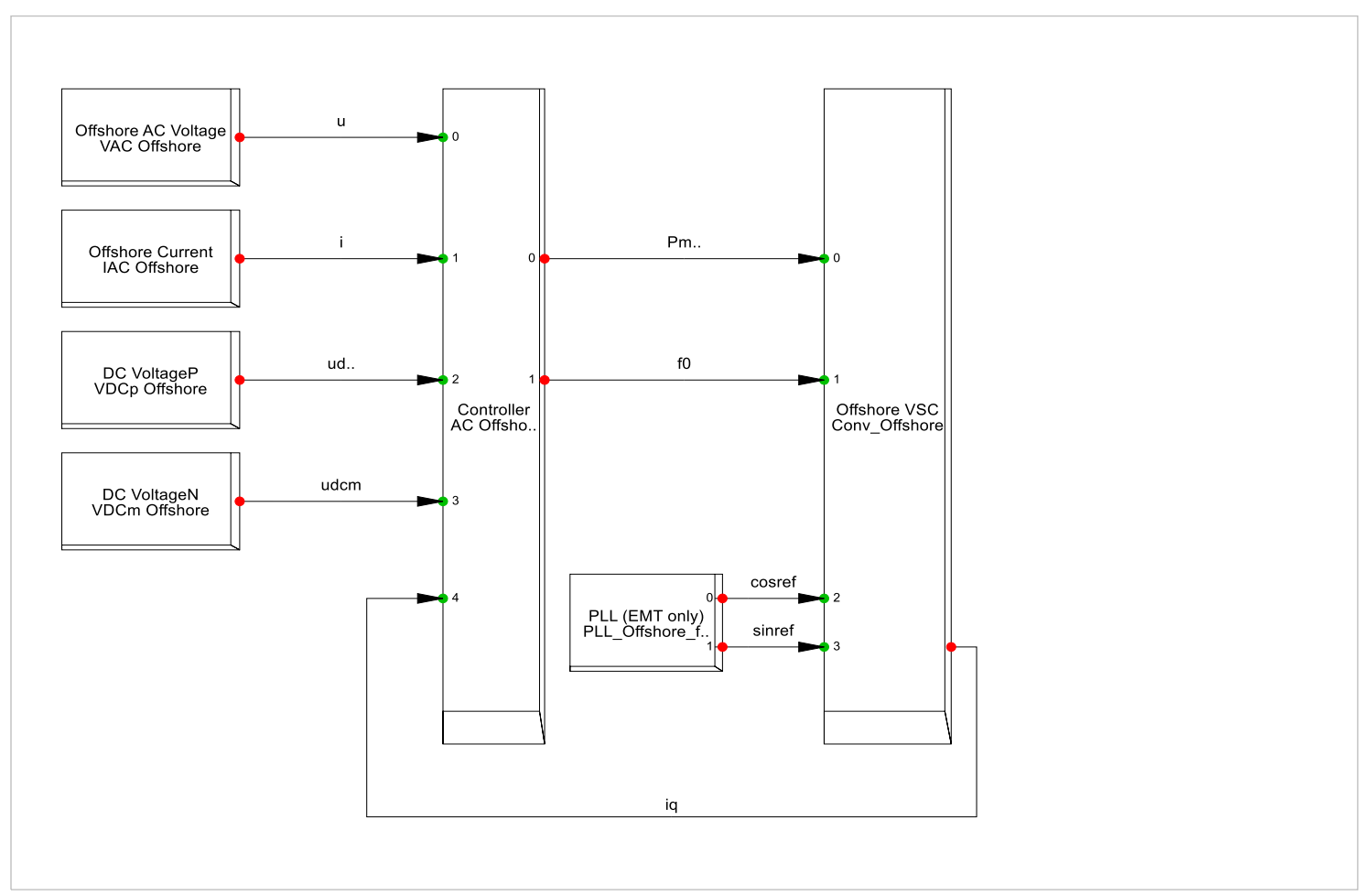

Şekil 8. Denizüstü HVDC kontrol sisteminin genel yapısı

Offshore Controller:

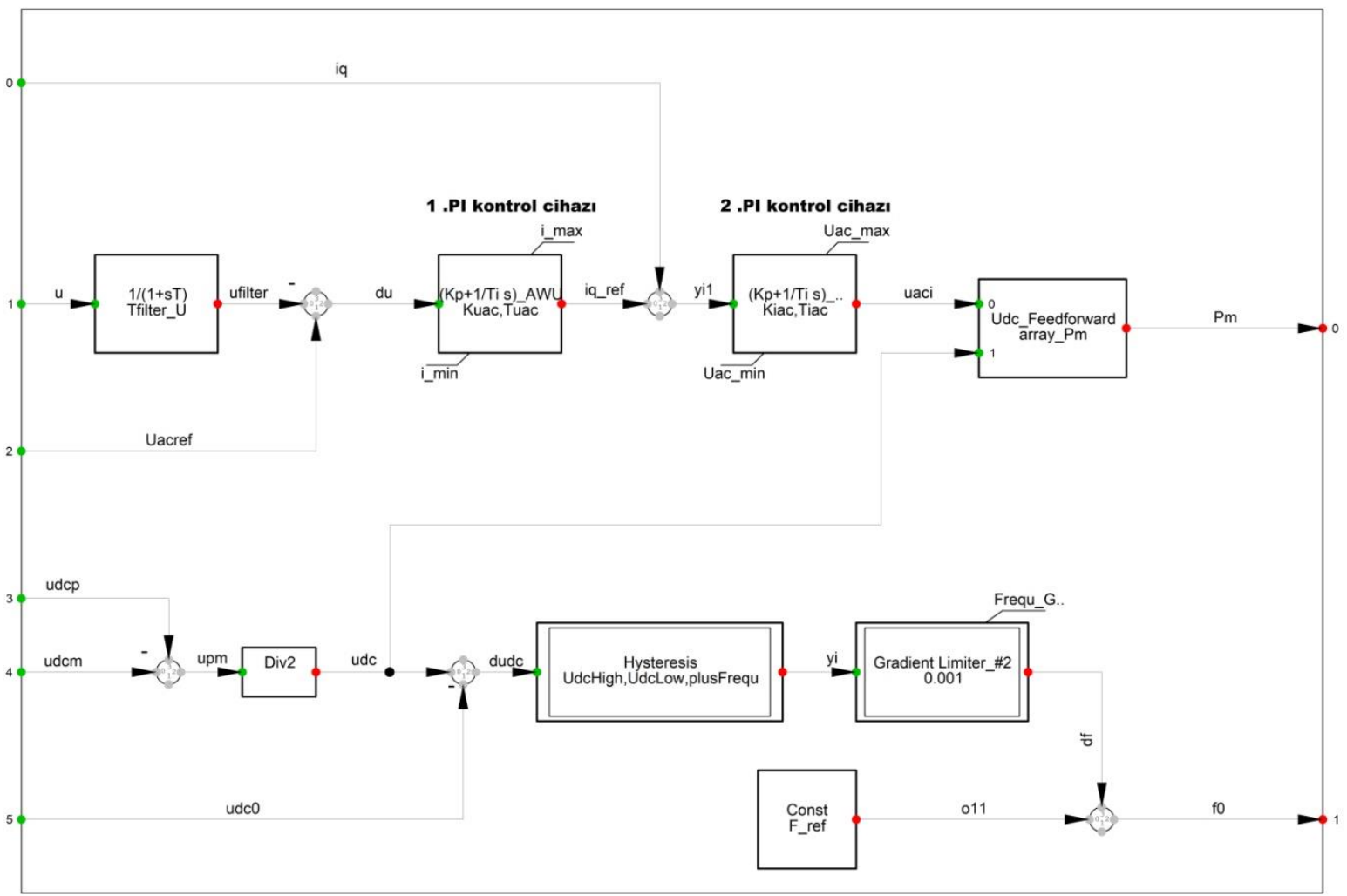

Şekil 9.Denizüstü dönüştürücü kontrolörün genel yapısı 


\subsection{4 İletim Sisteminin Modeli}

$\mathrm{Bu}$ çalı̧̧mada denizüstü/karaüstü rüzgâr santralinin etkilerinin inceleneceği 154 kV'lk 11 baralık Marmara iletim sisteminin kesiti Şekil 10'da görüldüğü gibidir. İletim hatlarının gerçek zamanlı çalışan sistemden alınan verileri ise Tablo 1'de görüldüğü gibidir (bu değerler km başına düşen değerlerdir). Tablo 1'de görülen $\mathrm{S}^{*}-5$ (baradan-baraya) görülen iletim hattı yaklaşı $14 \mathrm{~km}$ olarak kurgulanmıştır. Bu hat Denizüstü/karaüstü rüzgar santralinden gelen yükü 5 nolu Ezine barasına taşıyan iletim hattıdır. Baralara ait üretim/tüketim verilerinin tahmini değerleri ise Tablo 2'deki gibidir.

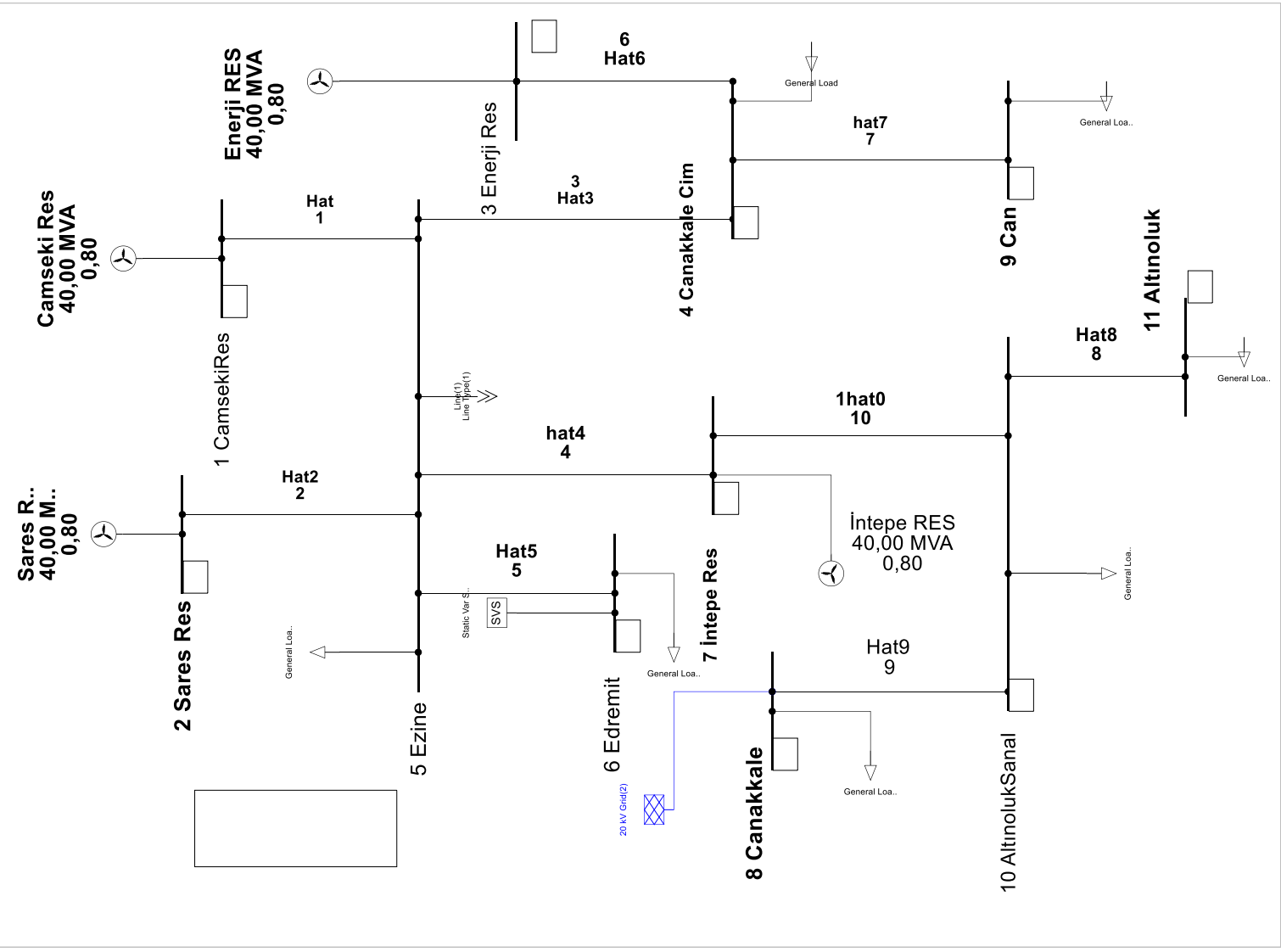

Şekil 10. Güç sisteminin tek hat şeması

Tablo 1.154 kV Enerji Illetim Hattına ait veriler

\begin{tabular}{l|l|l|l|l|l}
\hline $\mathrm{nl}$ & $\mathrm{nr}$ & $\mathrm{R} \mathrm{pu}$ & $\mathrm{X} \mathrm{pu}$ & $\mathrm{R}_{0} \mathrm{pu}$ & $\mathrm{X}_{0} \mathrm{pu}$ \\
\hline 1 & 5 & $0.026098 \mathrm{pu}$ & $0.197224 \mathrm{pu}$ & $0.167742 \mathrm{pu}$ & $0.598999 \mathrm{pu}$ \\
\hline 2 & 5 & $0.052174 \mathrm{pu}$ & $0.43783 \mathrm{pu}$ & $0.31532 \mathrm{pu}$ & $1.121644 \mathrm{pu}$ \\
\hline 5 & 4 & $0.052195 \mathrm{pu}$ & $0.394479 \mathrm{pu}$ & $0.335483 \mathrm{pu}$ & $1.197998 \mathrm{pu}$ \\
\hline 5 & 7 & $0.052195 \mathrm{pu}$ & $0.394479 \mathrm{pu}$ & $0.335483 \mathrm{pu}$ & $1.197998 \mathrm{pu}$ \\
\hline 5 & 6 & $0.052195 \mathrm{pu}$ & $0.394479 \mathrm{pu}$ & $0.335483 \mathrm{pu}$ & $1.197998 \mathrm{pu}$ \\
\hline 3 & 4 & $0.0822 \mathrm{pu}$ & $0.38577 \mathrm{pu}$ & $0.2936 \mathrm{pu}$ & $1.312 \mathrm{pu}$ \\
\hline 4 & 9 & $0.06946 \mathrm{pu}$ & $0.403469 \mathrm{pu}$ & $0.355375 \mathrm{pu}$ & $1.2057 \mathrm{pu}$ \\
\hline 10 & 11 & $0.134216 \mathrm{pu}$ & $0.421587 \mathrm{pu}$ & $0.423006 \mathrm{pu}$ & $1.225262 \mathrm{pu}$ \\
\hline 8 & 10 & $0.134216 \mathrm{pu}$ & $0.421587 \mathrm{pu}$ & $0.423006 \mathrm{pu}$ & $1.225262 \mathrm{pu}$ \\
\hline 7 & 10 & $0.052174 \mathrm{pu}$ & $0.437832 \mathrm{pu}$ & $0.315322 \mathrm{pu}$ & $1.121644 \mathrm{pu}$ \\
\hline $\mathrm{S} *$ & 5 & $0.134216 \mathrm{pu}$ & $0.421587 \mathrm{pu}$ & $0.423006 \mathrm{pu}$ & $1.225262 \mathrm{pu}$ \\
\hline
\end{tabular}


Tablo 2. 154 kV Güç Sistemine ait Bara değerleri

\begin{tabular}{|c|c|c|c|c|c|c|c|}
\hline \multirow[b]{2}{*}{$\begin{array}{l}\text { BaraN } \\
\text { o }\end{array}$} & \multirow[b]{2}{*}{$\begin{array}{l}\text { Bara } \\
\text { kod }\end{array}$} & \multicolumn{2}{|l|}{ Yuk } & \multicolumn{2}{|c|}{ Generator } & \multicolumn{2}{|l|}{ Generator } \\
\hline & & $\mathrm{P}$ & Q & $\mathrm{P}(\min )$ & $\mathrm{P}(\max )$ & $\mathrm{Q}(\min )$ & $\mathrm{Q}(\max )$ \\
\hline 1 & 2 & $0 \mathrm{MW}$ & 0 MVAR & $0 \mathrm{MW}$ & $20 \mathrm{MW}$ & $0 \mathrm{MW}$ & $4 \mathrm{MW}$ \\
\hline 2 & 2 & $0 \mathrm{MW}$ & 0 MVAR & $0 \mathrm{MW}$ & $24 \mathrm{MW}$ & 0 MVAR & 4 MVAR \\
\hline 3 & 2 & $0 \mathrm{MW}$ & 0 MVAR & $0 \mathrm{MW}$ & $30 \mathrm{MW}$ & -4 MVAR & 4 MVAR \\
\hline 4 & 0 & $45 \mathrm{MW}$ & 2 MVAR & $0 \mathrm{MW}$ & $0 \mathrm{MW}$ & 0 MVAR & 0 MVAR \\
\hline 5 & 2 & $60 \mathrm{MW}$ & 3 MVAR & $0 \mathrm{MW}$ & $85 \mathrm{MW}$ & -15 MVAR & 15 MVAR \\
\hline 6 & 0 & $10.5 \mathrm{MW}$ & 1.1 MVAR & $0 \mathrm{MW}$ & $0 \mathrm{MW}$ & 0 MVAR & 0 MVAR \\
\hline 7 & 2 & $0 \mathrm{MW}$ & 0 MVAR & $0 \mathrm{MW}$ & $30 \mathrm{MW}$ & -4 MVAR & 4 MVAR \\
\hline 8 & 0 & $40 \mathrm{MW}$ & 1.5 MVAR & $0 \mathrm{MW}$ & OMW & 0 MVAR & 0 MVAR \\
\hline 9 & 0 & $10 \mathrm{MW}$ & 0.2 MVAR & $0 \mathrm{MW}$ & $0 \mathrm{MW}$ & 0 MVAR & 0 MVAR \\
\hline 10 & 1 & $13 \mathrm{MW}$ & $1 \mathrm{MVAR}$ & - MW & - MW & - MVAR & - MVAR \\
\hline 11 & 0 & $12 \mathrm{MW}$ & 1 MVAR & $0 \mathrm{MW}$ & $0 \mathrm{MW}$ & 0 MVAR & 0 MVAR \\
\hline
\end{tabular}

\subsection{Yük Akış Analizi}

Güç sistemlerinde, güç üretiminin ve tüketiminin işletme sınırları içinde kalarak, yük akışının dengeli bir biçimde yapılması önemlidir. Yük akış analizi: Bara gerilimlerinin kabul edilebilir düzeyde olup olmadığı, farklı güç sistemi teçhizatlarının şebekenin yüklenmesine nasıl etki ettiği, güç sisteminin zayıf noktalarının ne olduğu, güç sisteminde kayıpların oranı, koruma koordinasyonun nasıl sağlıklı yapılacağı vb. önemli konularda bilgi verir (Akdağ ve ark., 2018). Böylece mevcut güç sistemi hakkında genel bir bilgi vererek, gelecek planlanmasının yapılmasına da olanak sağlar. Yük akış analizleri mevcut bir güç sisteminin sanal ortamda modellemesi yapılarak analiz edilebilir. Modelleme, simülasyon ve analiz güç sistemleri mühendisliği alanında yapılacak çalışmalarda, kaliteli bir sistem tasarlamada kullanılan önemli bir yöntemidir. Mevcut kurulu sistemlerde bir değişiklik yapılması Rus ruleti oynamaya benzer. Yapılan değişikliğin öngörülemeyen etkilerinin maliyeti çok yüksek olabilir. Ama bir sistemin sanal ortamda modelini oluşturup simülasyonu yapılırsa, sınırsız özgürlükle deneme yapma, değişikliklerin sonuçlarını görme imkânı yakalanmış olunur. Bu çalışmada 154 kV-11 baralık Marmara bölgesi iletim sistemi modellenerek, bu sisteminin 154 kV'luk Ezine barasına eklenilmesi düşünülen Denizüstü/karaüstü rüzgâr santralinin yük akış analizi yapılmıştır. Çalışmada yük akış analizinde güç sisteminde güç dengesini oluşturmak için DigSilent programında 10 nolu Altınoluk sanal barası (salınım barası) (slackbusbar) olarak seçilmiştir. Bu seçim ile bu baranın aktif gücü güç sistemine göre sürekli değiştirilerek denge sağlatılmaya çalışılmıştır. Aktif güç kontrolü bu şekilde dengelenmiştir. Reaktif güç kontrolü ise DigSilent yazılımında güç sistemindeki generatörlerin reaktif güç rezervleri kullanılarak yapılmıştır (1-2-3-5-7. Baralar). Güç sisteminde baralardaki gerilim değerlerinin işletme koşulları içinde kalmasında nispeten bu generatörlerin voltaj regülatörleri kullanılmıştır.

154 kV Marmara B. iletim sisteminde DigSilent yazılımında yük akış analizi yapılarak, test edilmiştir. Bu sistemde 1-2-3-5-7 nolu baralar üretim barası iken 10 nolu bara salınım barasıdır. Diğer baralar ise tüketim barasıdır (üretim baralarından 5 nolu Ezine barası ve 10 nolu salınım barasındada tüketimde mevcuttur). Tüm baralarda bara gerilimleri 0.95 pu ve 1.05 pu arasında olacak işletme sınırları arasında kalması istenilen durumdur. Yük akış analizi denizüstü/karaüstü santralin devrede olması/olmaması durumu göz önüne alınarak analizi yapılmıştır. Analiz sonuçları Tablo 3'de görüldüğü gibidir. 11 baralık Marmara Bölgesi fiderlerdeki bara gerilim değerleri denizüstü/karaüstü santralinin şebekeye aktardıkları güç ile değişmektedir. Bir güç sistemi, müşterilerinin istediği gücü karşılamalı ve bara gerilimleri işletme sınırları içinde kalmalıdır. Şebekede bulunan generatörler belirlenen limitler içinde çalışmalı ve şebeke ile trafolar aşırı yüklenmemelidir. Tablo 3 incelendiğinde denizüstü/karaüstü rüzgar santrallerinin devreye girmesi ile bara gerilim değerleri iyileşerek güç sisteminin gerilim kararlılığının daha da üst seviyeye çıkmasına katkı sağlamıştır. Yük akışı analizde denizüstü/karaüstü rüzgâr santralinin tam güç kapasitede olduğu durum alınarak analiz edilmiştir. Analizde santral $73.5 \mathrm{MW}$ aktif güç, 11.3 MVAR reaktif güç üretmiştir. Santral devreye girmeden önce güç sisteminde toplam aktif güç kayıpları (saatlik bazda) 9.03 MW iken santralin devreye girmesi ile bu kayıplar 7.83 MW seviyesine düşmüştür. Santralin devreye girmesi ile ortalama güç sisteminde yıllık 10368000kWH bir tasarruf sağlayacağı ön görülmektedir. 
YÜK AKIŞ ANALİZi SONUÇLARI

\begin{tabular}{|c|c|c|}
\hline & $\begin{array}{c}\text { DENİZ̈̈STÜ/ONSHORE } \\
\text { DEVREDE IKKEN }\end{array}$ & $\begin{array}{c}\text { DENİZÜSTÜ/ONSHORE } \\
\text { DEVREDE DEĞİL IKKEN }\end{array}$ \\
\hline$P_{1 G e n e r a t o r}$ & $20 \mathrm{MW}$ & $20 \mathrm{MW}$ \\
\hline $\mathrm{P}_{\text {2Generator }}$ & $24 \mathrm{MW}$ & $24 \mathrm{MW}$ \\
\hline $\mathrm{P}_{3 \text { Generator }}$ & $30 \mathrm{MW}$ & $30 \mathrm{MW}$ \\
\hline $\mathrm{P}_{5 \text { Generator }}$ & $73.5 \mathrm{MW}$ & $0 \mathrm{MW}$ \\
\hline P7Generator $_{\text {7 }}$ & $26 \mathrm{MW}$ & $26 \mathrm{MW}$ \\
\hline $\mathrm{P}_{10 G e n e r a t o r}$ & 18.2 MW & 93.1 MW \\
\hline $\mathrm{Q}_{1 \text { Generator }}$ & 0.5 MVAR & 0.5 MVAR \\
\hline $\mathrm{Q}_{\text {2Generator }}$ & 1.9 MVAR & 1.9 MVAR \\
\hline Q3Generator & 2 MVAR & 2 MVAR \\
\hline Q5Generator & 11.3 MVAR & 0 MVAR \\
\hline Q7Generator & 3.9 MVAR & 3.9 MVAR \\
\hline Q10Generator & 93.1 MVAR & -13.9 MVAR \\
\hline $\mathrm{V}_{1}$ & $153.9 \mathrm{kV}-1 \mathrm{pu}$ & $153.3 \mathrm{kV}-1 \mathrm{pu}$ \\
\hline $\mathrm{V}_{2}$ & $154 \mathrm{kV}-1 \mathrm{pu}$ & $154 \mathrm{kV}-1 \mathrm{pu}$ \\
\hline$V_{3}$ & $153.9 \mathrm{kV}-1 \mathrm{pu}$ & $153.2 \mathrm{kV}-0.99 \mathrm{pu}$ \\
\hline $\mathrm{V}_{4}$ & $153.9 \mathrm{kV}-1 \mathrm{pu}$ & $153.2 \mathrm{kV}-0.99 \mathrm{pu}$ \\
\hline $\mathrm{V}_{5}$ & $153.9 \mathrm{kV}-1 \mathrm{pu}$ & $153.2 \mathrm{kV}-0.99 \mathrm{pu}$ \\
\hline $\mathrm{V}_{6}$ & $150.9 \mathrm{kV}-0.98 \mathrm{pu}$ & $150.3 \mathrm{kV}-0.98 \mathrm{pu}$ \\
\hline $\mathrm{V}_{7}$ & $152.7 \mathrm{kV}-0.99 \mathrm{pu}$ & $157.4 \mathrm{kV}-1.02 \mathrm{pu}$ \\
\hline $\mathrm{V}_{8}$ & $153.6 \mathrm{kV}-1 \mathrm{pu}$ & $153.6 \mathrm{kV}-1 \mathrm{pu}$ \\
\hline $\mathrm{V}_{9}$ & $153.5 \mathrm{kV}-1 \mathrm{pu}$ & $152.8 \mathrm{kV}-0.99 \mathrm{pu}$ \\
\hline $\mathrm{V}_{10}$ & $153.9 \mathrm{kV}-1 \mathrm{pu}$ & $154 \mathrm{kV}-1 \mathrm{pu}$ \\
\hline $\mathrm{V}_{11}$ & $152.99 \mathrm{kV}-0.99 \mathrm{pu}$ & $152.9 \mathrm{kV}-0.99 \mathrm{pu}$ \\
\hline $\begin{array}{c}\text { Denizüstü/Onshore } \\
\text { AC bara }\end{array}$ & $154 \mathrm{kV}-1 \mathrm{pu}$ & \\
\hline Pdemand & 190.5 MW & $190.5 \mathrm{MW}$ \\
\hline Ptotalkayıp & $7.83 \mathrm{MW}$ & $9.03 \mathrm{MW}$ \\
\hline
\end{tabular}

\subsection{Kısa Devre Arıza Analizi}

Bu çalışmada mevcut sistemine büyük ölçekli denizüstü/karaüstü rüzgâr santralinin entegrasyonu ile kısa devre seviyesindeki değişimlerden dolayı bütün halinde güç sisteminin kısa devre arıza analizi yapılması gerekir. Kısa devre seviyesindeki değişimler ile mevcut güç sistemindeki teçhizatların bara kısa devre dayanım sınırlarını zorlayıp zorlamadığını tespit edilebilir. Ayrıca değiş̧en bu akım değerlerine göre enerjinin sürekliliği sağlanması yönünden korunma koordinasyonun doğru yapılması için kısa devre arıza analizleri oldukça önemlidir. Kısa devre hesaplamalarında 3 fazlı kısa devre arızası güç sistemi için en riskli durumu belirtir. Bu yüzden çalışmada 3 faz kısa devre arızası üzerinde durulmuştur. DigSilent yazılımı ile denizüstü/karaüstü rüzgâr santrali devre değil iken yapılan $154 \mathrm{kV}$ Çanakkale ve civarı iletim sistemindeki tüm baralarda 3 faz kısa devre arıza analizi sonuçları Şekil 11'de görüldüğü gibidir. Kısa devre arıza analizlerinde IEC-60909 standardı seçilmiş̧ir. 


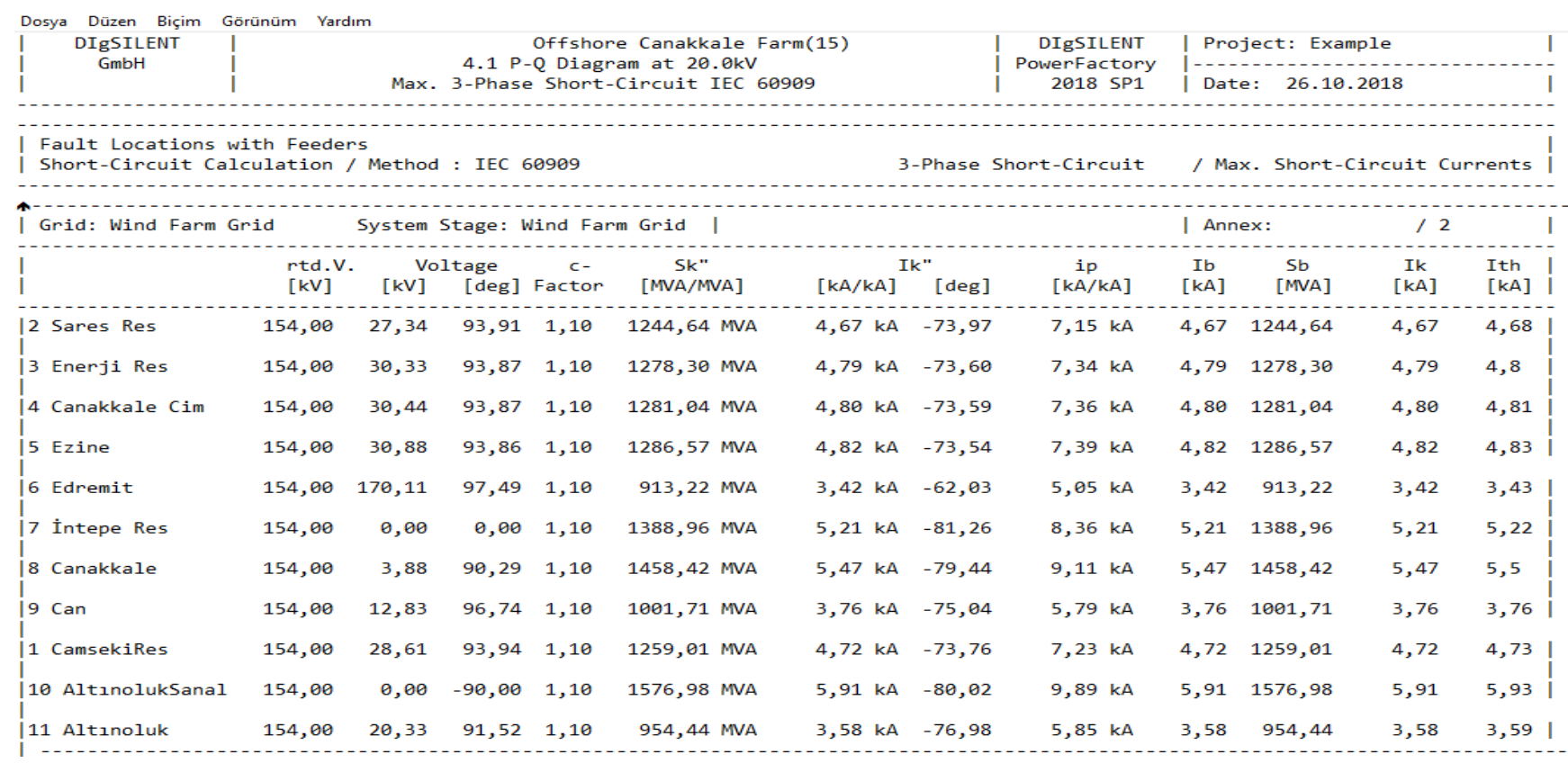

Şekil 11. Denizüstü/onshore santral devrede değil iken 3 faz kısa devre arızası sonucu oluşan veriler

DigSilent yazılımı ile denizüstü/karaüstü rüzgar santrali devrede iken yapılan 3 faz kısa devre arıza analiz sonuçları Şekil 12’de görüldüğü gibidir.

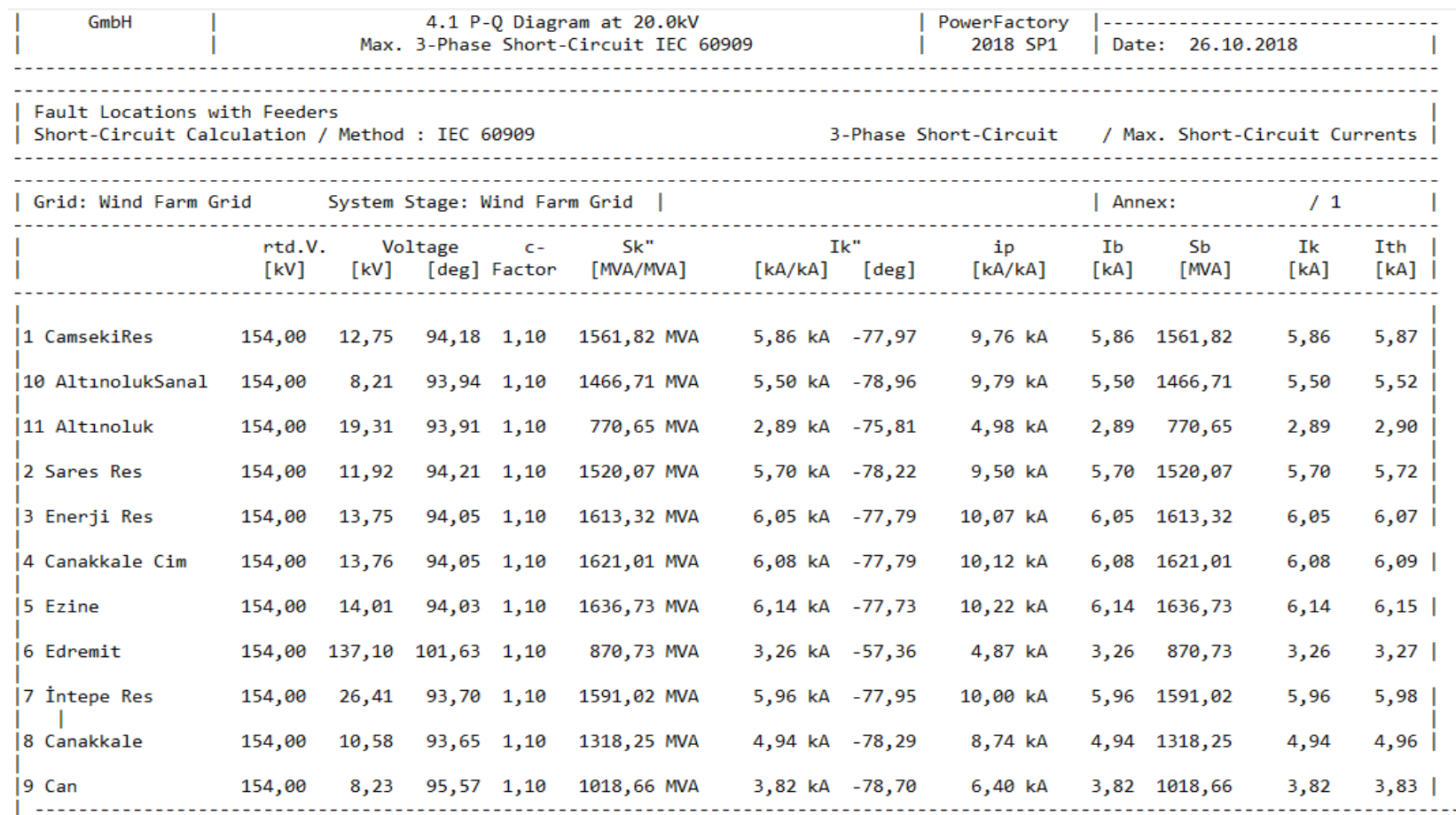

Şekil 12. Denizüstü/onshore santral devrede iken 3 faz kısa devre arızası sonucu oluşan veriler

Sonuç olarak 3-faz arıza analizi ile denizüstü/karaüstü rüzgâr santralinin bağlı olduğu Ezine barasında 3 faz arıza akım değeri santral devrede değil iken $4.82 \mathrm{kA}$ iken santral devreye girdiğinde $6.14 \mathrm{kA}$ olmuştur. Bu değer Elektrik Şebeke Yönetmeliğinin Madde-14'de iletim sistemi şalt teçhizatı için kısa devre arıza akımına dayanma kapasitesi; $154 \mathrm{kV}$ için $31.5 \mathrm{kA}$, belirlenmesi hükmü ile uyumlu olduğu görülmüştür (EŞY, 2014).

\subsection{Dinamik Simulasyon Analizi}

Dinamik simulasyon analizi paketi orta ve uzun vadeli simülasyon çalışmalarında kullanılan zamana bağlı yük akış analizi yapmaya yarayan DigSilent'a ait bir modüldür. Bu modül ile simülasyon periyodu ve simülasyon adım aralığı gibi parametreler 
belirlemek mümkündür. Bu özellik ile güç sisteminin istenilen işletme koşullarında sistem performansı hakkında bilgiler alınabilir. Bu çalışmada ofshore/karaüstü rüzgâr santralinin belli bir zaman aralığında güç sistemine etkisi analiz edilmiştir. Güç sistemlerinde gerilim kararlılığı nominal işletme koşullarında olan bir güç sisteminde geriliminin istenilen sınırlarda kalması ile ifade olur. İlgili baraya ait gerilim dalgalanması 0.95 pu-1.05 pu sınırlarında kalması istenilir (EŞY, 2014). Örnek güç sisteminde, denizüstü/karaüstü rüzgar santralinin 28.10.2018-28.11.2018 tarihleri arasında gün içinde minimum \%10, maksimum \%95 kapasite ile 11 baralık Marmara iletim sistemine aktif güç verecek şekilde bir işletme senaryosu oluşturulsun. Şekil 13'de gösterilen ve ilgili güç sistemine Denizüstü/karaüstü santraline ait baranın gerilim değeri $0.95 \mathrm{pu}$ ve $0.99 \mathrm{pu}$ aralığında kaldığı görülmektedir. Böylece santral belirlenen zaman aralığında istenilen gerilim aralığında kalmıştır.

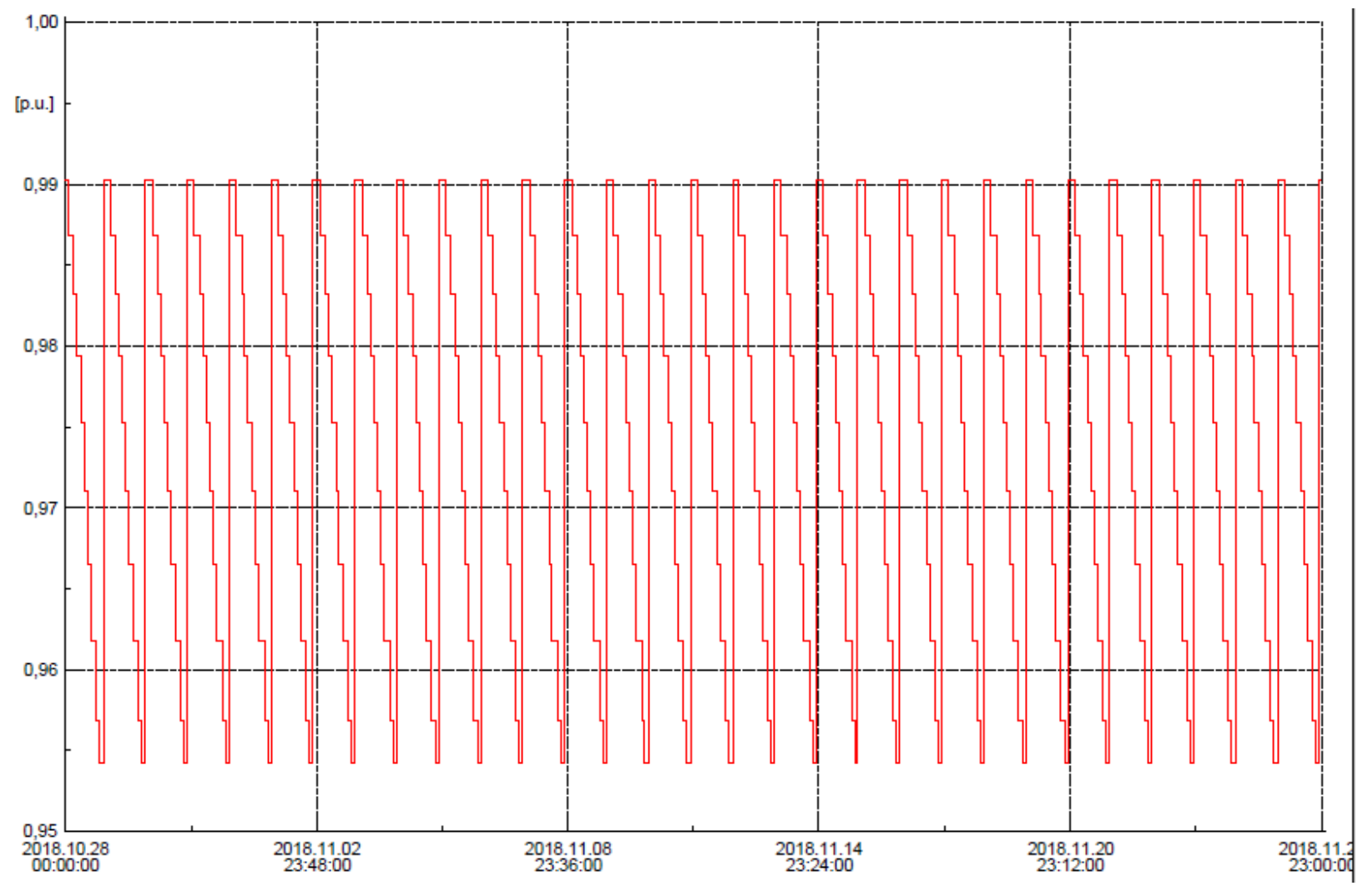

Şekil 13. Denizüstü/Onshore santraline ait baradaki gerilim değeri

\subsection{Reaktif Güç Kapasite Analizi}

Bu çalışmada, karaüstü rüzgâr santrali parkının 2.5 MW gücündeki rüzgâr tribünlerinin ilgili şebekeye tedarik edeceği reaktif güç oranını gösteren eğri Şekil 14'de görüldüğü gibidir. Bu eğri yardımıyla reaktif güç kapasitesi analizi yapılmıştır (Samancıŏ̆lu, 2016). Reaktif güç kapasite analizleri P-Q ve V-Q diyagramlarının çizdirilerek yorumlanması ile analiz edilir. P-Q diyagramı her bir aktif güç değerine karşılık gelen reaktif güç tedariğini temsil eder. Bu eğri ile kabul edilebilir işletme çalışma alanında, sınır işletim rejim koşullarını gösteririr. Sınır işletim değerleri Şekil 14'deki gibi baz alınarak DigSilent yazılımında P-Q eğrisi çizdirilir. Benzetimi yapılan karaüstü rüzgâr tribünlerinin P-Q eğrisi, T.C. Enerji Bakanlığının Elektrik Piyasası Şebeke Yönetmeliğinde belirlediği kapasite eğrisinin tamamını kapsayacak şekilde olması istenir (EŞY, 2014). Bu çalışmada şebeke yönetmeliğinde belirtilen sınır değerlerine göre DigSilent yazılımının DPL program geliştirme arayüzünde girilerek çizdirilir (DGT, 2018). Daha sonra karaüstü rüzgâr santralinin P-Q eğrisi, yönetmelik de belirtilen hususlara göre çizilen eğriyi kapsaması istenilir. Şekil 15 incelendiğinde kırmızı ile çizilen karaüstü rüzgâr santrali P-Q eğrisi, mavi ile çizilen yönetmeliğe ait P-Q eğrisini kapsadığı görülmektedir. Sonuç olarak karaüstü rüzgâr santrali gerekli reaktif güç desteğini ilgili şebekeye sağlayacaktır. 


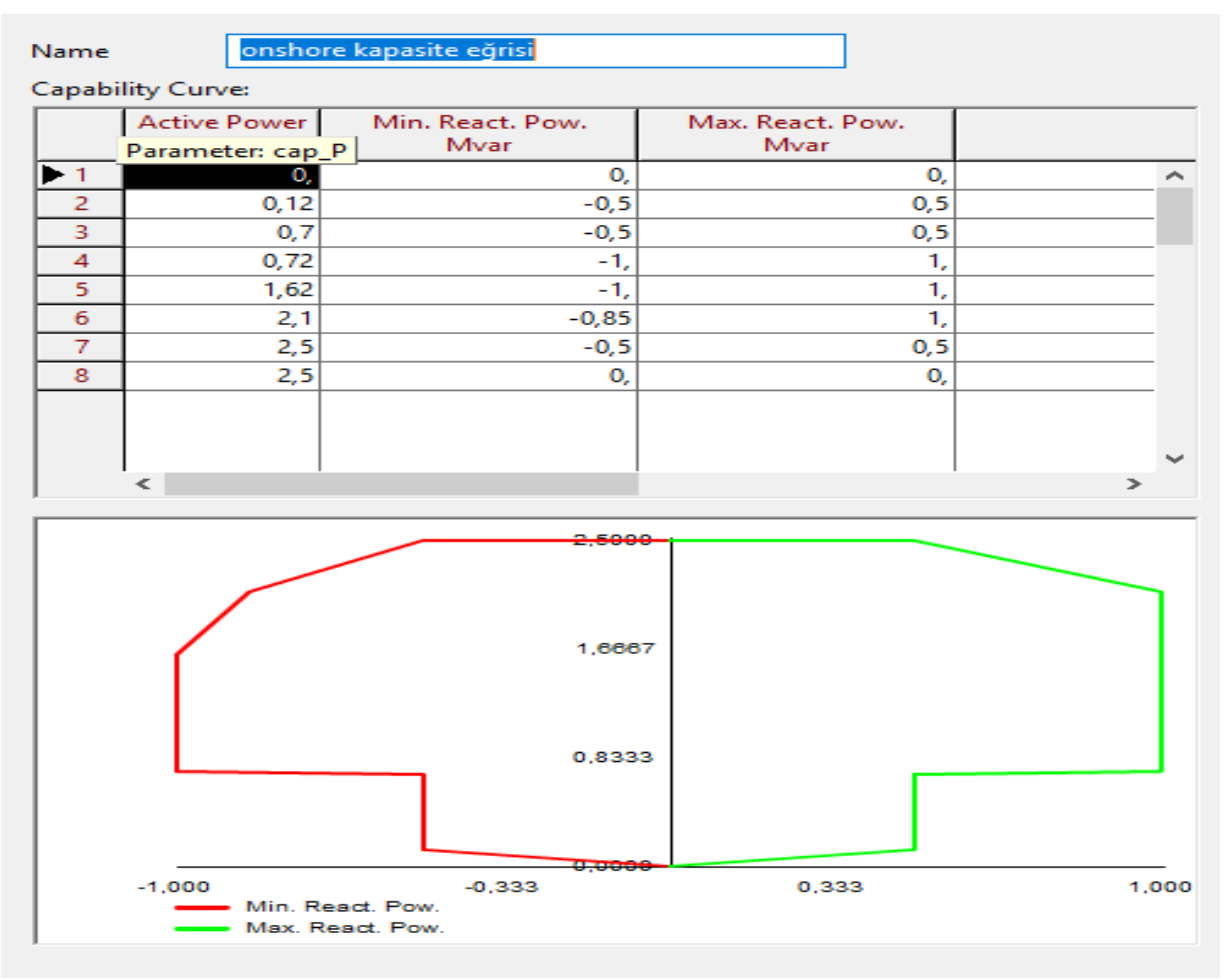

Şekil 14. Onshorerüzgar santralinin tribünlerine ait kapasite ĕgrisi

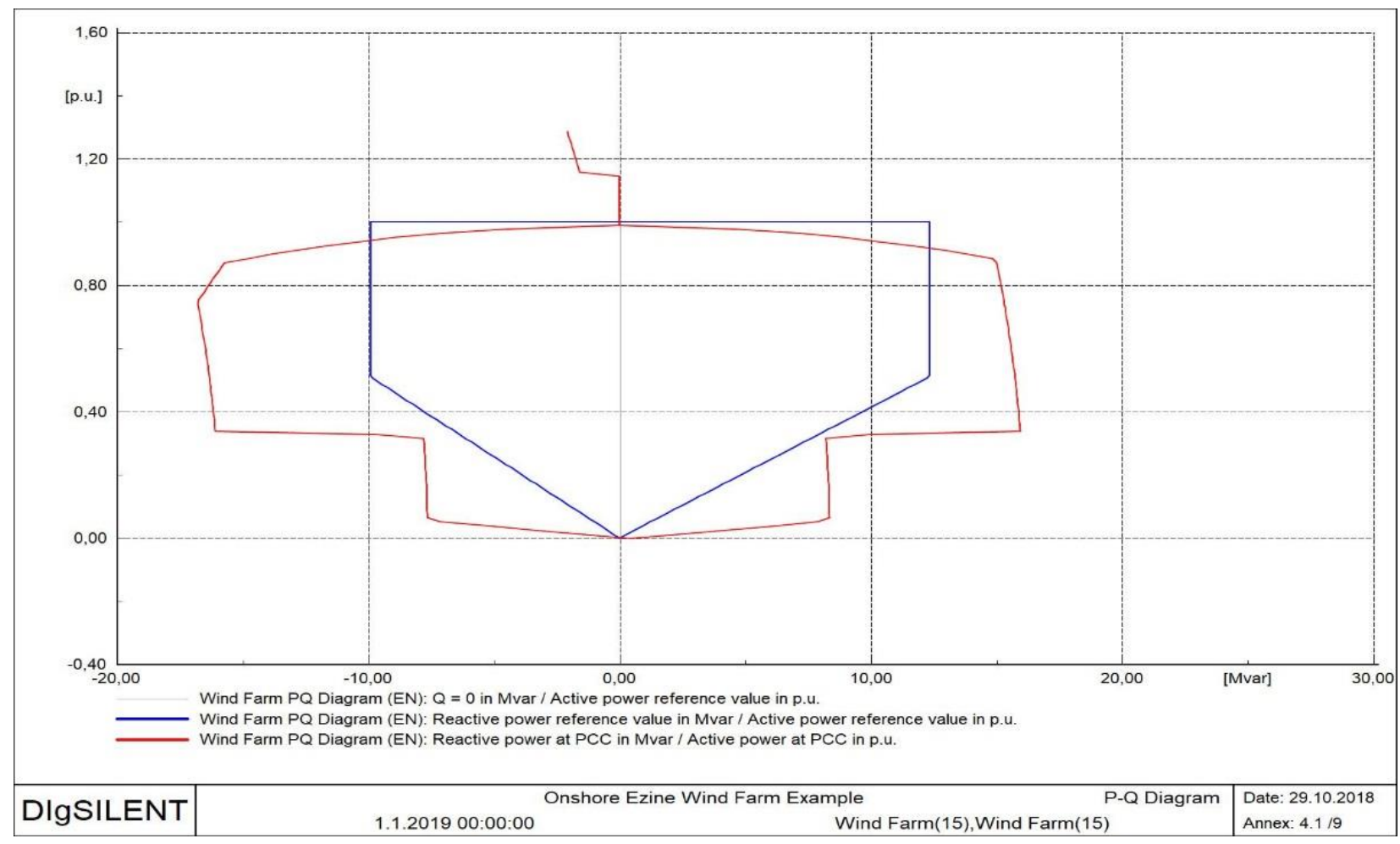

Şekil 15. Onshore santrale ait $P / Q$ diyagramı

V-Q diyagramı ise sistemin kararlılık durumu hakkında bilgi verebilir. V-Q diyagramı karaüsü rüzgâr santralinin reaktif güç tedarik kapasite uygunluğunu gösteren diyagramdır. Şayet bu diyagram ile yönetmelikde belirtilen hususları sağlarsa, güç sisteminin geriliminin değeri istenilen aralıkta tutulabilir (EŞY, 2014). Bu gerilim sınırları çalışmada 0.9 ve 1.1 pu aralığında çizilmiştir. V-Q diyagramı DigSilent yazılımında P-Q diyagramı çizilme aşamasında anlatılan yol ile DPL kodları kullanılarak Şekil 16'da görüldüğü gibi çizdirilmiştir (DGT, 2018). Şekil 16'da kırmızı ile çizilen eğri rüzgâr jeneratörlerinin eğrisidir. Mavi eğri ise sisteme ait V-Q eğrisidir. Kırmızı eğrinin mavi eğriyi kapsaması istenilen durumdur. Bu çalışmada karaüstü rüzgâr santral, şebeke bağlantı noktası gerilimine göre V-Q eğrisini sağladığı görülmüştür. 


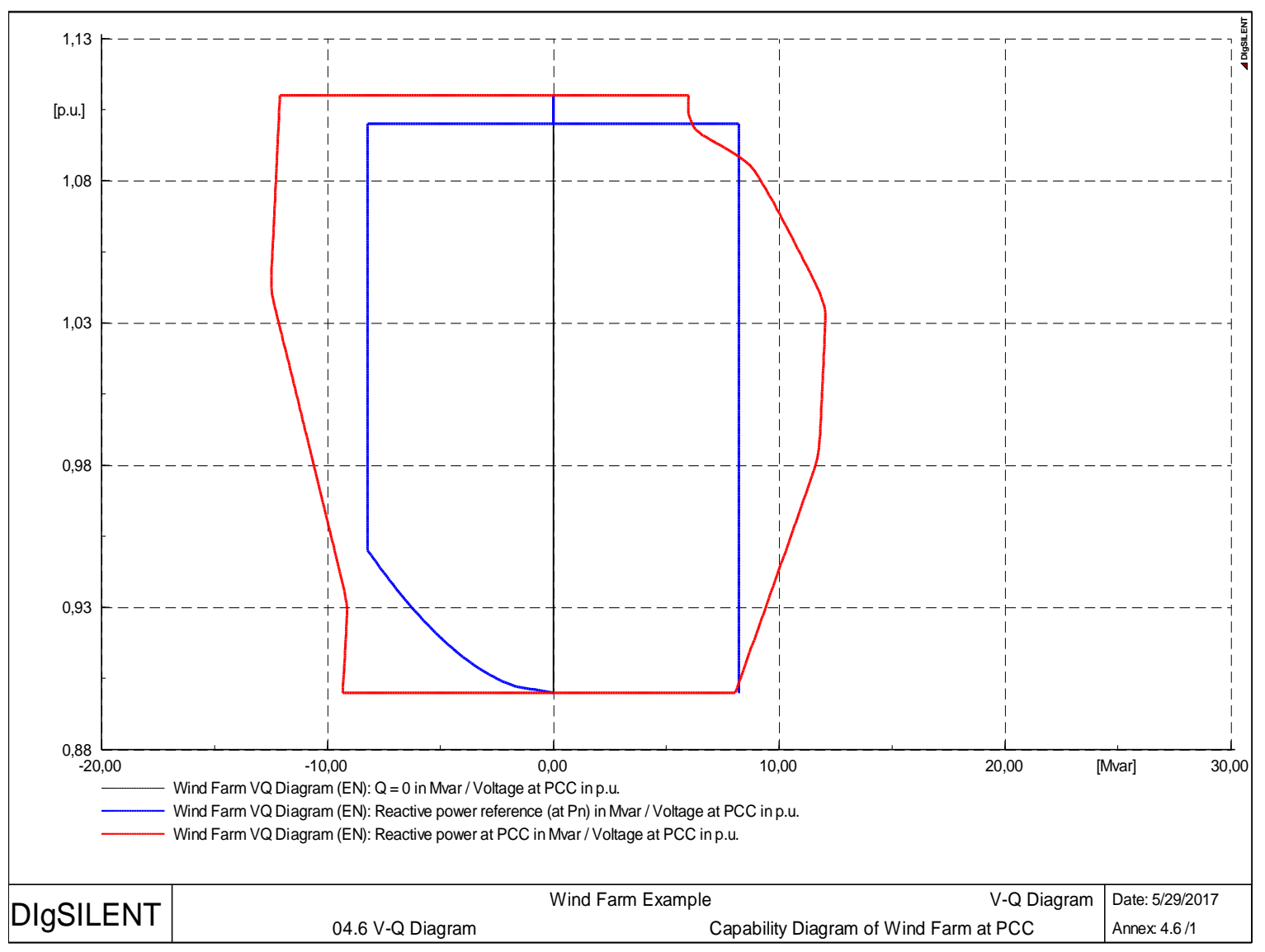

Şekil 16. Onshorerüzgar ait V/Q diyagramı

\section{Sonuç}

Yenilenebilir enerji kaynaklarından biri olan denizüstü/karaüstü rüzgâr santraline tüm dünyada olduğu gibi ülkemizdede ilgi artmaktadır. Kurulumuna 2018 sonunda başlanılacak olan denizüstü rüzgâr santrali ülkemizin ilk ve dünyanın en büyük deniz üstü rüzgâr enerji santrali olma özelliğini taşıması ile ülkemizin 2023 enerji politikasında önemli bir yer tutmaktadır. Bu yönü ile önemi gittikçe artan denizüstü/karaüsü rüzgâr santrali çalışmalarına örnek olması açısından bu yayında bu konu ele alınmıştır. Denizüstü rüzgâr santrallerinin kurulacağı bölgelerde (deniz aşırı bölgeler) daha kararlı ve yüksek rüzgâr hızlarının bulunması sebebiyle klasik rüzgâr santrallerine göre daha fazla üretim yapma kapasitesine sahiptir. Denizüstü rüzgâr santralinin kurulacağı bölgelerde rüzgâr potansiyelinin yüksek oluşu bu santralin karaüstü santraller ile birlikte tasarlanıp kurulmasına olanak sağlar. Denizüstü/karaüsü rüzgâr santralleri anlık değişen rüzgâr hızına göre belli aralık da değişen enerji üretimi yapması nedeniyle ilave edileceği güç sisteminin kalitesi üzerinde çeşitli etkilere sahiptir. Bu etkilerin iyi analiz edilerek istenilen işletme koşullarında kalması için, denizüstü/ karaüsü rüzgâr santrali kurulacak sahanın ön etüt (fizibilite) çalışmaları ile uygun şekilde belirlenip daha sonra santralin ilgili bölge özelliklerine göre modellenip bazı analizlerin yapılması önemlidir. Bu yayında denizüstü/karaüstü rüzgâr santralinin kurulacağı bölge için ön etüt çalışması yapılarak ülkemizde uygun saha belirlenmiştir. Daha sonra denizüstü/karaüstü rüzgar santralinin ilgili entegre edileceği 11 baralık $154 \mathrm{kV}$ Marmara iletim sistemi ile modellenmesi yapılmıştır. Ayrıca ilerde ülkemizde HVDC iletim hatlarının yaygınlaşması durumu göz önüne alınarak, denizüstü rüzgâr santralinin modellenmesinde VSC-HVDC sistemi ile entegrasyonu, ana dinamik modelleme ve temel kontrol özelliklerinden bahsedilmiştir. Daha sonra bu santralin bölge iletim sistemine entegre edilmesinde yönetmelikçe belirlenen koşullara bağlı kalınarak bazı önemli şebeke uyumluluk analizleri yapılmıştır. Şebeke uyumluluk analizleri ile santralin mevcut güç sistemine etkisi görülemeye çalışılmıştır. Denizüstü/onshore santralin yapılan yük akış analizinde ilgili güç sistemi baralarında bara gerilimleri $0.95 \mathrm{pu}$ ve 1.05 pu seviyelerine yakın seviyelerde olması ile optimum bir yük akışı sağlatılmaya çalışılmıştır. Ayrıca santralin uzun vadede devrede olduğu bir süreçte dinamik yük akış analizi yapılarak sistemin gerilim kararlığına etkisi incelenmiştir. Çalışmada ilgili bölge ile birlikte denizüstü/karaüstü rüzgâr santralinin kısa devre analizi yapılmıştır. Bu çalışmada 3 faz kısa devre arızası tüm baralarda hesaplanarak, denizüstü/karaüstü rüzgâr santralinin kısa devre akımlarına katkısı yorumlanmıştır. Sonrasında reaktif güç kapasite analizi detaylı bir şekilde yapılarak, karaüstü rüzgâr santralinin güç sistemine reaktif katkısı analiz edilmiştir. Elde edilen analiz sonuçları ile denizüstü/karaüstü santralinin ilgili bölge sistemine uygun entegrasyonu sağlatılmaya çalışılmıştır. Böylece, bu çalışma ilgili bölge için yapılacak diğer çalışmalara yol gösterici olması öngörülmektedir. 


\section{Kaynakça}

AKDAĞ, O., OKUMUŞ, F., Kocamaz, A. F., \& YEROĞLU, C. (2018). Fractional Order Darwinian PSO with Constraint Threshold for Load Flow Optimization of Energy Transmission System. Gazi University Journal of Science, 31(3), 831-844.

Argin, M., \& Yerci, V. (2017). Denizüstü wind power potential of the Black Sea region in Turkey. International Journal of Green Energy, 14(10), 811-818.

Cali, U., Erdogan, N., Kucuksari, S., \& Argin, M. (2018). Techno-economic analysis of high potential Denizüstü wind farm locations in Turkey. Energy strategy reviews, 22, 325-336.

Canakkale, (2017). http://www.eie.gov.tr/YEKrepa/MALATYA-REPA.pdf (07.06.2017)

DGT (2018). Digsilent Technical Documentation. DIgSILENTPowerFactory Application Guide DPL TutorialDIgSILENT Technical Documentation. Technical report, DIgSILENTGmbH, GomaringenGermany.

DIgSILENT (2018). HVDC Connected Denizüstü Wind Farm. Technical report, DIgSILENT, Gomaringen Germany.

EŞY, (2014). Elektrik Şebeke Yönetmeliği, Resmi Gazete, 28 Mayıs 2014.

Efe, S., B. (2014). Mikro Şebekelerde Güç Akış Analizi, Doctoral Thesis. Firat University, Elazı̆̆, Turkey.

Jerkø, A. (2014). Reactive Power and Voltage Control of Denizüstü Wind Farms (Master's thesis, Institutt for elkraftteknikk).

Karık, F., Sözen, A., \& İzgeç, M. M. (2017). Rüzgâr gücü tahminlerinin önemi: Türkiye elektrik piyasasında bir uygulama. Politeknik Dergisi, 20(4), 851-861.

Koroglu, M., O., (2011). Yüksek gerilim alternatif akım ve yüksek gerilim doğru akım şebeke bağlantılı denizüstü (Denizüstü) rüzgâr santrallerinin tasarım esasları, Master Thesis, Ege University, İzmir, Turkey.

Nanou, S. I., \& Papathanassiou, S. A. (2016). Grid code compatibility of VSC-HVDC connected Denizüstü wind turbines employing power synchronization control. IEEE Transactions on Power Systems, 31(6), 5042-5050.

Perez Collazo, C., Astariz, S., Abanades, J., Greaves, D., \& Iglesias, G. (2014). Co-located wave and Denizüstü wind farms: A preliminary case study of an hybrid array. In International conference in coastal engineering (ICCE).

PowerFactory (EN), (2017). User Manual; http://www.digsilent.de/index.php/downloads.html (01.05.2017)

Samancioglu, G., (2014). Rüzgar havza planlaması ve rüzgar santrallerinin şebekeye olan etkilerinin dıgsılent programı ile modellemesi, Master Thesis, Gazi University, Ankara, Turkey.

Satir, M., Murphy, F., \& McDonnell, K. (2018). Feasibility study of an Denizüstü wind farm in the Aegean Sea, Turkey. Renewable and Sustainable Energy Reviews, 81, 2552-2562.

Shah, R., Barnes, M., \& Preece, R. (2016). Modelling and Dynamic Analysis of a Power System with VSCHVDC Radial Plus Strategy.

Suwan, M., Jordanien, A., (2017). Modelingand Control of VSC-HVDC Connected Denizüstü WindFarms, DoctoralThesis, Von der FakultätfürIngenieurwissenschaften, Duisburg, Germany.

Van de Sandt, R., Lowen, J., Paetzold, J., \& Erlich, I. (2009). Neutral earthing in off-shore wind farm grids. In 2009 IEEE Bucharest PowerTech (pp. 1-8). IEEE. 